This is an author produced version of a paper published in Advances in Agronomy. This paper has been peer-reviewed. It does not include the final journal pagination.

Citation for the published paper:

Bo Stenberg, Raphael A. Viscarra Rossel, Abdul Mounem Mouazen, and Johanna Wetterlind, Visible and Near Infrared Spectroscopy in Soil Science. In Donald L. Sparks, editor: Advances in Agronomy, Vol. 107, Burlington: Academic Press, 2010, pp. 163-215. http://dx.doi.org/10.1016/S0065-2113(10)07005-7

Access to the published version may require journal subscription.

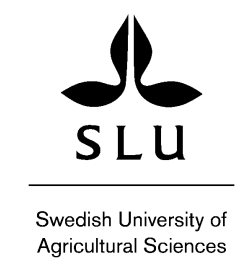

Epsilon Open Archive http://epsilon.slu.se 


\title{
Visible and near infrared spectroscopy in soil science
}

\author{
Bo Stenberg ${ }^{\mathrm{a}^{*}}$, Raphael A. Viscarra Rossel ${ }^{\mathrm{b}}$, Abdul Mounem Mouazen ${ }^{\mathrm{c}}$, Johanna Wetterlind ${ }^{\mathrm{d}}$ \\ $\mathrm{a}^{*}$ Department of Soil and Environment, Swedish University of Agricultural Sciences, PO Box 234, SE-532 \\ 23 Skara, Sweden Tel: +46 511 67276, Fax: +46 511 67134, E-mail: bo.stenberg@mark.slu.se \\ (Corresponding author)
}

${ }^{\mathrm{b}}$ CSIRO Land \& Water, Bruce E. Butler Laboratory, GPO Box 1666 Canberra ACT 2601, Australia, Email: raphael.viscarra-rossel@csiro.au

cNatural Resources Department, Cranfield University, MK43 0AL, United Kingdom, E-mail:

a.mouazen@cranfield.ac.uk

${ }^{\mathrm{d}}$ Department of Soil and Environment, Swedish University of Agricultural Sciences, PO Box 234, SE-532

23 Skara, Sweden, E-mail: Johanna.wetterlind@mark.slu.se

\begin{abstract}
This chapter provides a review on the state of soil visible-near infrared (vis-NIR) spectroscopy. Our intention is for the review to serve as a source of up-to date information on the past and current role of vis-NIR spectroscopy in soil science. It should also provide critical discussion on issues surrounding the use of vis-NIR for soil analysis and on future directions. To this end, we describe the fundamentals of visible and infrared diffuse reflectance spectroscopy and spectroscopic multivariate calibrations. A review of the past and current role of vis-NIR spectroscopy in soil analysis is provided, focusing on important soil attributes such as soil organic matter ( $\mathrm{SOM})$, minerals, texture, nutrients, water, $\mathrm{pH}$, and heavy metals. We then discuss the performance and generalization capacity of vis-NIR calibrations, with particular attention on sample pre-tratments, co-variations in data sets, and mathematical data preprocessing. Field analyses and strategies for the practical use of vis-NIR are considered. We conclude that the technique is useful to measure soil water and mineral composition and to derive robust calibrations for SOM and clay content. Many studies show that we also can predict properties such as $\mathrm{pH}$ and nutrients, although their robustness may be questioned. For future work we recommend that research should focus on: (i) moving forward with more theoretical calibrations, (ii) better understanding of the complexity of soil and the physical basis for soil reflection, and (iii) applications and the use of spectra for soil mapping and monitoring, and for making inferences about soils quality, fertility and function. To do this, research in soil spectroscopy needs to be more collaborative and strategic. The development of the Global Soil Spectral Library might be a step in the right direction.
\end{abstract}




\section{Contents}

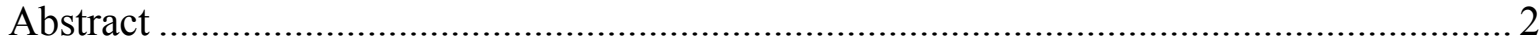

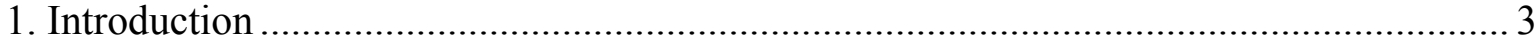

1.1. Fundamentals of soil visible and infrared diffuse reflectance spectroscopy............... 4

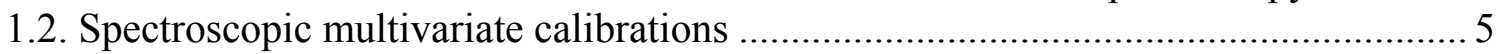

1.3. Considerations for developing spectroscopic calibrations ....................................... 6

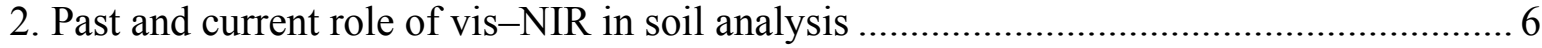

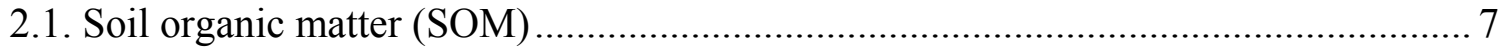

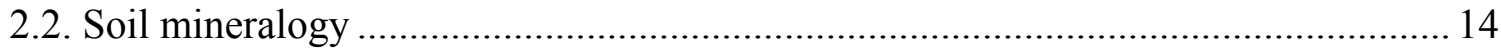

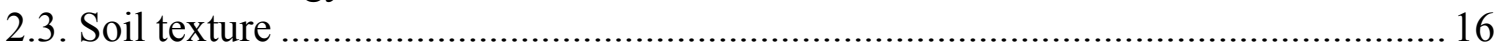

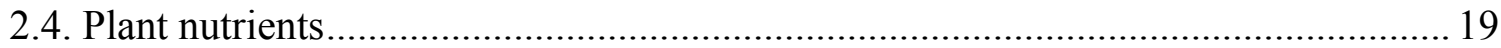

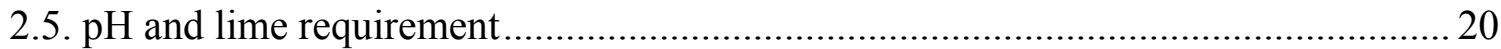

2.6. Organic matter quality and microbial processes ………….................................... 20

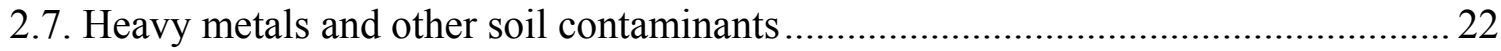

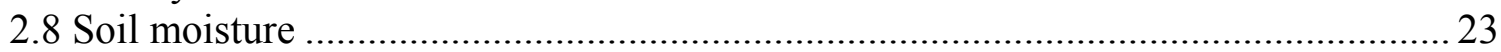

3. Factors influencing the performance and generality of vis-NIR calibrations...................25

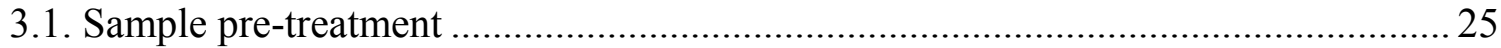

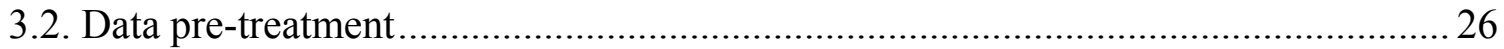

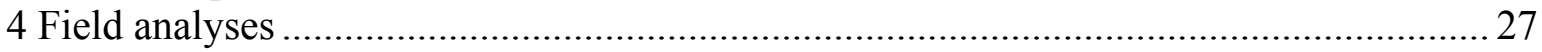

5. Strategies for practical use of vis-NIR spectroscopy for soil analysis ............................ 28

5.1. Local influence of target area................................................................................. 30

5.2 Screening and mapping of overall soil variability ……………................................. 31

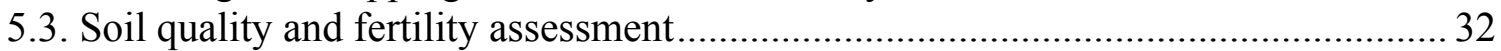

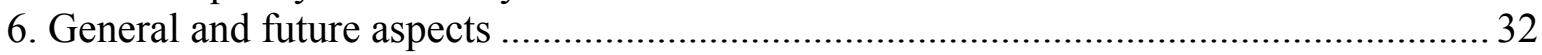

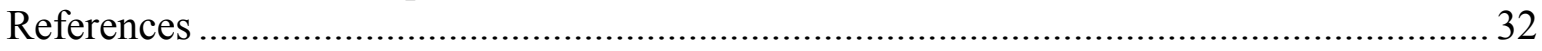

\section{Introduction}

Soil is a fundamental natural resource which people rely on for the production of food, fiber, and energy. Soil is a regulator of water movement in the landscape, it is an environmental filter for metals, nutrients, and other contaminants that may leach into the environment, it is a biological habitat and gene reserve and is the foundation for buildings and other constructions. Soil is also regarded as a potential sink for carbon to mitigate global warming. The ability of a soil to support any of these functions depends on its structure; composition; and chemical, biological, and physical properties, all of which are both spatially and temporally variable (Blum, 1993; Bouma, 1997; Harris et al., 1996; Jenny, 1980; Karlen et al., 1997).

Fundamentally, soil is a complex matrix that consists of organic and inorganic mineral matter, water, and air. The organic material in soils ranges from decomposed and stable humus to fresh, particulate residues of various origins. The distribution of these different organic pools in soil influences biological activity, nutrient availability and dynamics, soil structure and aggregation, and water-holding capacity (Skjemstad et al., 1997). The inorganic mineral fraction is often described by its particle size distribution (proportions of sand, silt, and clay) and also by additional subclasses in various classification systems (Hillel and Hillel, 1998). Coarse sand particles typically consist of resistant minerals such as quartz and feldspars, while fine particles consist of various clay minerals that have undergone various degrees of weathering. Thus, the mineral fraction can be defined by the parent material, soil age, climate, relief, and position in the landscape ( Jenny, 1980). Different clay minerals have different properties, for example, some are able to hold water in their lattices, giving them their shrink-swell behavior, while others are important as a source of potassium on weathering (Andrist-Rangel et al., 2006). Clay particles are characterized by negatively charged surfaces and some clay minerals have more negatively charged surfaces than others. 
This is important in terms of the physics and chemistry of the soil as these charged surfaces regulate aggregation processes and the cat ion exchange capacity (CEC) of the soil, which affects the release and retention of nutrients as well its buffering capacity (Hillel and Hillel, 1998).

No two soils are exactly alike and variations occur over short distances, vertically and horizontally. Given the importance of soils, there is a need for regular monitoring to detect changes in its status so as to implement appropriate management in the event of degradation. Soil surveying may be performed at national levels for the inventory of soil resources, or for agriculture at regional, farm or field scales, for example, to monitor carbon, nutrient status, $\mathrm{pH}$, and salinity.

Recognition by farmers of the high variability of soils, even within fields, and the advent of global positioning systems (GPS) facilitating real time positions have led to the development of the concept of precision agriculture (PA) or site-specific agriculture. PA aims to improve resource use efficiency by variable rate applications to supply a crop with precisely what it requires at a high spatial resolution (Robert et al., 1991).

As a consequence of global warming, there is also much focus on developing soil management practices supporting carbon sequestration in soils to reduce atmospheric carbon dioxide. Intensive and reliable mapping is required to monitor changes in soil organic pools (Bricklemyer et al., 2005; Mooney et al., 2004). All these aspects require accurate inexpensive soil analysis.

Over the past two decades, research on the use of visible-near infrared (vis-NIR) diffuse reflectance spectroscopy in soil science has increased rapidly (Ben-Dor and Banin, 1995a; Bowers and Hanks, 1965; Brown et al., 2006; Shepherd and Walsh, 2002; Stenberg et al., 1995; Sudduth et al., 1989; Viscarra Rossel and McBratney, 1998; Wetterlind et al., 2008b). The main focus has been on basic soil composition, particularly soil organic matter (SOM), texture, and clay mineralogy, but also nutrient availability and properties such as fertility, structure, and microbial activity. There are many reasons for the interest in vis-NIR. For example, sample preparation involves only drying and crushing, the sample is not affected by the analysis in any way, no (hazardous) chemicals are required, measurement takes a few seconds, several soil properties can be estimated from a single scan, and the technique can be used both in the laboratory and in situ (Viscarra Rossel et al., 2006c).

The aim of this chapter is to provide a review on the current state of vis-NIR spectroscopy in soil science. We begin by describing some of the fundamentals of soil diffuse reflectance spectroscopy, as well as the spectroscopic calibrations needed to estimate soil properties. We then review and discuss the use of visNIR for estimating important soil properties and examine the influence of external factors, such as experimental design and sample and spectral pretreatments, on the calibrations. We then consider the potential for field vis-NIR measurements and strategies for its practical implementation, and finish by providing a synthesis and discuss the future of vis-NIR spectroscopy.

\subsection{Fundamentals of soil visible and infrared diffuse reflectance spectroscopy}

To generate a soil spectrum, radiation containing all relevant frequencies in the particular range is directed to the sample. Depending on the constituents present in the soil the radiation will cause individual molecular bonds to vibrate, either by bending or stretching, and they will absorb light, to various degrees, with a specific energy quantum corresponding to the difference between two energy levels. As the energy quantum is directly related to frequency (and inversely related to wavelength), the resulting absorption spectrum produces a characteristic shape that can be used for analytical purposes (Miller, 2001). The frequencies at which light is absorbed appear as a reduced signal of reflected radiation and are displayed in \% reflectance $(R)$, which can then be transformed to apparent absorbance: $A=\log (1 / R)$ (Fig. 1). The 
wavelength at which the absorption takes place (i.e., the size of the energy quantum) depends also on the chemical matrix and environmental factors such as neighboring functional groups and temperature, allowing for the detection of a range of molecules which may contain the same type of bonds.

When NIR radiation interacts with a soil sample, it is the overtones and combinations of fundamental vibrations in the mid-infrared (mid-IR) region that are detected. Molecular functional groups can absorb in themid-IR, with a range of progressively weaker orders of overtones detected in both the mid-IR and NIR regions. General ly, the NIR region is characterized by broad, superimposed, and weak vibrational modes, giving soilNIRspectra few, broad absorption features (Fig. 1). In the visible region, electronic excitations are the main processes as the energy of the radiation is high.

Due to the broad and overlapping bands, vis-NIR spectra contain fewer absorptions than the mid-IR and can be more difficult to interpret (Fig. 1). Nevertheless, this region contains useful information on organic and inorganic materials in the soil. Absorptions in the visible region (400-780 nm) are primarily associated with minerals that contain iron (e.g., haematite, goethite) (Mortimore et al., 2004; Sherman and Waite, 1985). SOM can also have broad absorption bands in the visible region that are dominated by chromophores and the darkness of organic matter. Absorptions in the NIR region (780-2500 nm) result from the overtones of $\mathrm{OH}, \mathrm{SO} 4$, and $\mathrm{CO} 3$ groups, as well as combinations of fundamental features of $\mathrm{H} 2 \mathrm{O}$ and $\mathrm{CO} 2$ (e.g., Clark, 1999). Clay minerals can show absorption in the vis-NIR region due to metal-OH bend plus $\mathrm{O}-\mathrm{H}$ stretch combinations (Viscarra Rossel et al., 2006a). Carbonates also have weak absorption peaks in the near infrared (Hunt and Salisbury, 1970). Water has a strong influence on vis-NIR spectra of soils. The dominant absorption bands of water around 1400-1900 nm are characteristic of soil spectra (Fig. 1), but there are weaker bands in other parts of the vis-NIR range (Liu et al. 2002).

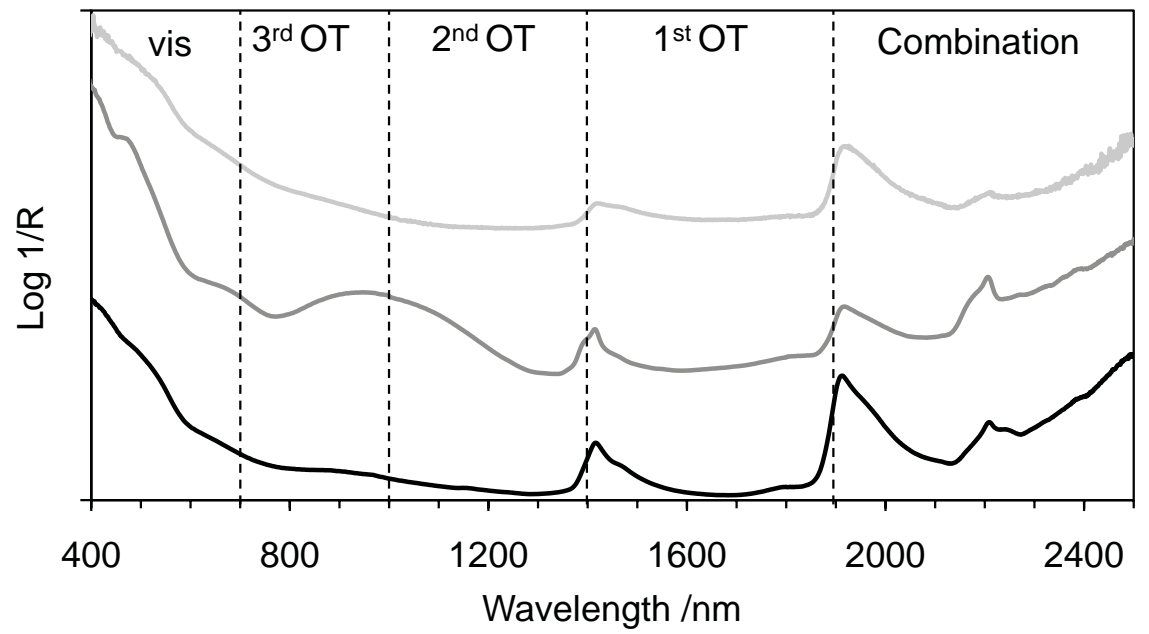

Figure 1. Soil vis-NIR 400-2500 $\mathrm{nm}$ spectra showing approximately where the combination, first, second, and third overtone (OT) vibrations occur, as well as the visible (vis) range.

\subsection{Spectroscopic multivariate calibrations}

Diffuse reflectance spectra of soil in the vis-NIR are largely nonspecific due to the overlapping absorption of soil constituents. This characteristic lack of specificity is compounded by scatter effects caused by soil structure or specific constituents such as quartz. All of these factors result in complex absorption patterns that need to be mathematically extracted from the spectra and correlated with soil properties. Hence, the analyses of soil diffuse reflectance spectra require the use of multivariate calibrations (Martens and Naes, 1989). The most common calibration methods for soil applications are based on linear regressions, namely stepwise multiple linear regression (SMLR) (Ben-Dor and Banin, 1995a; Dalal and Henry, 1986), 
principal component regression (PCR), and partial least squares regression (PLSR). The main reason for using SMLR is the inadequacy of more conventional regression techniques such as multiple linear regression (MLR) and lack of awareness among soil scientists of the existence of full spectrum data compression techniques such as PCR and PLSR. Both of these techniques can cope with data containing large numbers of predictor variables that are highly collinear. PCR and PLSR are related techniques and inmost situations their prediction errors are similar. However, PLSR is often preferred by analysts because it relates the response and predictor variables so that the model explains more of the variance in the response with fewer components, it is more interpretable and the algorithm is computationally faster. The use of data mining techniques such as neural networks (NN) (e.g., Daniel et al., 2003; Fidencio et al., 2002), multivariate adaptive regression splines (MARS) (Shepherd and Walsh, 2002), and boosted regression trees (Brown et al., 2006) is increasing. Viscarra Rossel (2007) combined PLSR with bootstrap aggregation (bagging-PLSR) to improve the robustness of the PLSR models and produce predictions with uncertainty. MLR, PCR, and PLS are linear models, while the data mining techniques can handle nonlinear data. Viscarra Rossel and Lark (2009) used wavelets combined with polynomial regressions to reduce the spectral data, account for non linearity and produce accurate and parsimonious calibrations based on selected wavelet coefficients. Mouazen et al. (2010) compared NN with PCR and PLS for the prediction of selected soil properties. They found combined PLSR-NN models to provide improved predictions as compared to PLSR and PCR. Viscarra Rossel and Behrens (2010) compared the use of PLSR to a number of data mining algorithms and feature selection techniques for predictions of clay, organic carbon and $\mathrm{pH}$. They compared MARS, random forests (RF), boosted trees (BT), support vector machines (SVM), NN, and wavelets. Their results suggest that data mining algorithms produce more accurate results than PLSR and that some of the algorithms provide information on the importance of specific wavelength in the models so that they can be used to interpret them.

\subsection{Considerations for developing spectroscopic calibrations}

When developing multivariate calibrations, careful selection of the calibration and validation samples is important. The size and distribution of the calibration data set has to be representative not only of the variation in the soil property being considered, but also of the variation in the spectra. It is also important that the validation samples are independent of the calibration samples. That is, validation samples should have no influence on the calibration procedure and no influence on the selection of the best calibration. In the literature, suspected pseudo-independent validation samples are fairly common. This risk occurs when the validation set is randomly selected from a heterogeneous sample set consisting of several internally homogeneous subsets. Examples are series of soil core increments or multiple plots in field experiments. Adjacent core increments and plots from the same trial could be expected to be very similar and could be more or less regarded as replicates. Such situations are likely to overestimate the predictive performance of a calibration. Brown et al. (2005) came to this conclusion by comparing the random sampling of six field trials with the calibration of only five trials predicting the sixth. As indicated by their results the later validation strategy may in turn exaggerate prediction errors compared with amore representative and homogeneously distributed calibration set. Only two of the six sites were poorly predicted compared with the random validation and the difference in prediction error of those to the random validation was largely explained by bias. Still, their study emphasizes the importance of selecting a validation strategy that represents the diversity of expected future samples.

\section{Past and current role of vis-NIR in soil analysis}

Over the last few decades a large number of attempts have been made to predict soil properties with visNIR. Calibrations for total and organic carbon are probably most frequent, followed by clay content. According to a review of published explained variance statistics (Viscarra Rossel et al., 2006c), these two, together with total soil N, are also those with the best chance of success. This makes sense because both clay minerals and SOM are the fundamental constituents of the soil and have well-recognized absorption features in the vis-NIR region. Some other frequently reported properties include $\mathrm{pH}$, extractable $\mathrm{P}, \mathrm{K}, \mathrm{Fe}$, $\mathrm{Ca}, \mathrm{Na}, \mathrm{Mg}$, and $\mathrm{CEC}$, as well as properties that are dependent on combinations of other soil properties, 
such as lime requirement and mineralisable N. Results for these are typically moderate and often highly variable. This makes sense as the co-variations to constituents that are spectrally active cannot be expected to be globally stable.

Table 1. Band assignments for fundamental mid-IR absorptions of soil constituents and their overtones and combinations in the vis-NIR. Compilation adapted from Viscarra Rossel \& Behrens (2010).

\begin{tabular}{|c|c|c|c|}
\hline Organics & Fundamental $\left(\mathrm{cm}^{-1}\right)$ & vis-NIR wavelength (nm) & vis-NIR Mode \\
\hline Aromatics & $v_{1} \mathrm{C}-\mathrm{H} 3030 \mathrm{~cm}^{-1}$ & $\begin{array}{l}1650 \\
1100 \\
825\end{array}$ & $\begin{array}{l}2 v_{1} \\
3 v_{1} \\
4 v_{1}\end{array}$ \\
\hline Amine & $\begin{array}{l}\delta \mathrm{N}-\mathrm{H} 1610 \mathrm{~cm}^{-1} \\
v_{1} \mathrm{~N}-\mathrm{H} 3330 \mathrm{~cm}^{-1}\end{array}$ & $\begin{array}{l}2060 \\
1500 \\
1000 \\
751\end{array}$ & $\begin{array}{l}v_{1} \delta \\
2 v_{1} \\
3 v_{1} \\
4 v_{1}\end{array}$ \\
\hline $\begin{array}{l}\text { Alkyl asymmetric- } \\
\text { symmetric doublet }\end{array}$ & $\begin{array}{l}v_{3} \text { C-H } 2930 \mathrm{~cm}^{-1} \\
v_{1} \text { C-H } 2850 \mathrm{~cm}^{-1}\end{array}$ & $\begin{array}{l}1706 \\
1754 \\
1138 \\
1170 \\
853 \\
877\end{array}$ & $\begin{array}{l}2 v_{3} \\
2 v_{1} \\
3 v_{3} \\
3 v_{1} \\
4 v_{3} \\
4 v_{1}\end{array}$ \\
\hline Carboxylic acids & $v_{1} \mathrm{C}=\mathrm{O} 1725 \mathrm{~cm}^{-1}$ & $\begin{array}{l}1930 \\
1449\end{array}$ & $\begin{array}{l}3 v_{1} \\
4 v_{1}\end{array}$ \\
\hline Amides & $v_{1} \mathrm{C}=\mathrm{O} 1640 \mathrm{~cm}^{-1}$ & $\begin{array}{l}2033 \\
1524\end{array}$ & $\begin{array}{l}3 v_{1} \\
4 v_{1}\end{array}$ \\
\hline Aliphatics & $v_{1} \mathrm{C}-\mathrm{H} 1465 \mathrm{~cm}^{-1}$ & $\begin{array}{l}2275 \\
1706\end{array}$ & $\begin{array}{l}3 v_{1} \\
4 v_{1}\end{array}$ \\
\hline Methyls & $v_{1} \mathrm{C}-\mathrm{H} 1445-1350 \mathrm{~cm}^{-1}$ & $\begin{array}{l}2307-2469 \\
1730-1852\end{array}$ & $\begin{array}{l}3 v_{1} \\
4 v_{1}\end{array}$ \\
\hline Phenolics & $v_{1} \mathrm{C}-\mathrm{OH} 1275 \mathrm{~cm}^{-1}$ & 1961 & $4 v_{1}$ \\
\hline Polysaccharides & $v_{1} \mathrm{C}-\mathrm{O} 1170 \mathrm{~cm}^{-1}$ & 2137 & $4 v_{1}$ \\
\hline Carbohydrates & $v_{1} \mathrm{C}-\mathrm{O} 1050 \mathrm{~cm}^{-1}$ & 2381 & $4 v_{1}$ \\
\hline
\end{tabular}

\subsection{Soil organic matter (SOM)}

SOM, often approximated to 1.72 times soil organic carbon (SOC), is the property most frequently estimated by vis-NIR calibrations. Organic molecules fundamental vibrations occur in the mid-IR and their overtones and combination bands occur in the vis-NIR region. Overtones and combination bands in vis-NIR due to organic matter result from the stretching and bending of $\mathrm{NH}, \mathrm{CH}$, and $\mathrm{CO}$ groups (BenDor et al., 1999; Bokobza, 1998; Goddu and Delker, 1960). Bands around 1100, 1600, 1700 to1800, 2000, and 2200 to $2400 \mathrm{~nm}$ have been identified as being particularly important for SOC and total N calibration (Ben-Dor and Banin, 1995a; Dalal and Henry, 1986;Henderson et al., 1992; Krishnan et al., 1980; Malley et al., 2000; Martin et al., 2002; Morra et al., 1991; Stenberg, 2010). Clark (1999) assigned bands near 2300, 1700, and $1100 \mathrm{~nm}$ to combination bands and first and second overtones, respectively, of the $\mathrm{C}-\mathrm{H}$ stretch fundamentals near $3400 \mathrm{~nm}\left(2900 \mathrm{~cm}^{-1}\right)$. This has been confirmed with humic acids extracted from a Chinese (Xing et al., 2005) and a Massachusetts (Kang and Xing, 2005) soil, where peaks at $3413 \mathrm{~nm}$ $\left(2930 \mathrm{~cm}^{-1}\right)$ and $3509 \mathrm{~nm}\left(2850 \mathrm{~cm}^{-1}\right)$ were ascribed to aliphatic $\mathrm{CH} 2$ stretching (Table 1). However, making specific assignments from a vis-NIR spectrum is difficult, as several other organic and inorganic molecules may absorb in these regions (Clark et al., 1990; Goddu and Delker, 1960). This is particularly 
so at longer wavelengths beyond $2000 \mathrm{~nm}$. Viscarra Rossel and Behrens (2010) present a summary of important fundamental absorptions in the mid-IR and the occurrence of their overtones and combinations in the vis-NIR, which can be used to help with interpretation (Table 1). In Fig. 2 the influence of SOM in vis-NIR is exemplified.

While the absorptions by SOM in the vis-NIR are often weak and not readily apparent to the naked eye (Fig. 2), the overall absorption due to SOM in the visible region is broad but clear (Baumgardner et al., 1985; Bowers and Hanks, 1965; Krishnan et al., 1980). For this reason, a number of studies have used soil color to estimate SOM (e.g., Viscarra Rossel et al., 2006b, 2008b). Thus there are various reports suggesting that vis-NIR relates better to SOM than the NIR alone (Viscarra Rossel et al., 2006c). For example, Islam et al. (2003) achieved considerably better results for Australian soils by including the visible region (350-700 nm) in the calibration and similar observations have been reported for Norwegian soils (Fystro, 2002). Udelhoven et al. (2003) suggested that the brightness of the sample is an important factor in the visible region for prediction of organic C content. However, In Swedish agricultural soils including the visible range in calibrations resulted in only small improvements (Stenberg, 2010) whereas the opposite was reported for US land resource areas (Chang et al., 2001) and south-eastern Australia (Dunn et al., 2002). Although the general observation is that soil becomes darker with increasing organic matter, many soil properties, such as texture, structure, moisture, and mineralogy, can influence this (Hummel et al., 2001), implying that darkness would only be a useful discriminator within a limited geological variation.

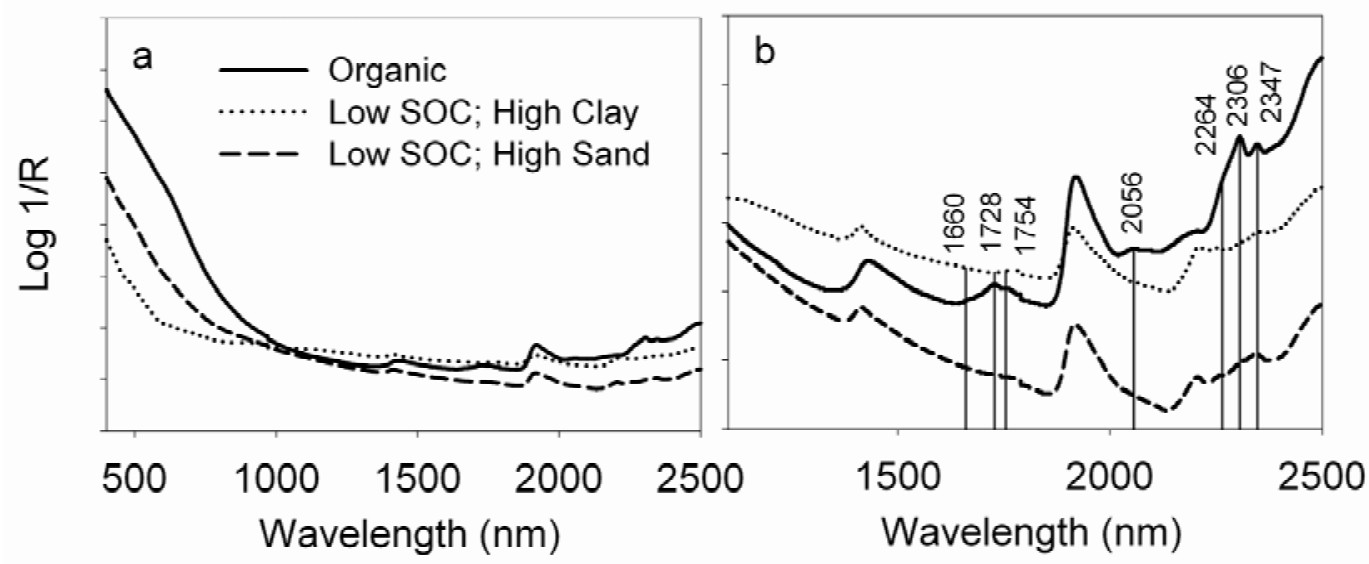

Figure 2. (A) Soil vis-NIR 400-2500 nm spectra and (B) the region 1100-2500 nm showing the spectra of three soils: an organic agricultural soil with $40 \%$ SOC and two with $1 \%$ SOC of which one has $87 \%$ sand and $4 \%$ clay, and the other $12 \%$ sand and $44 \%$ clay. Drop lines in $(\bar{B})$ indicate wavelengths typical of organic matter.

The performance of SOM and SOC calibrations is highly variable (Table 2). There are several possible explanations for this. Despite the numerous absorption bands of organic matter over the vis-NIR region, it is often reported that organic matter signals in this region are weak (e.g., Viscarra Rossel and McBratney, 1998), particularly in soils that contain only a few percent organic matter in a highly variable mineral matrix. Udelhoven et al. (2003) compared predictions of SOM in two regions of Germany and found that those based on a data set from the Eifel region were poorer than those based on data from the Hunsrück region. The authors explained this difference by the lower range of concentrations and higher geological variability in the Eifel soil. Stratification of the samples according to geological conditions and derivation of individual PLSR calibrations for each region produced better results.

Ben-Dor and Banin (1995a) suggested that the organic matter itself changes in quality with quantity in a way that influences spectra due to the stage of decomposition. In their study, in one group of soils with up 
Table 2. Validation results for SOC or total $\mathrm{C}\left(\mathrm{mg} \mathrm{g}^{-1}\right)$ with background data, sample and data pre-treatments. Farm-scale data sets and below are not included.

\begin{tabular}{|c|c|c|c|c|c|c|c|c|c|c|c|}
\hline $\begin{array}{l}\text { Sample } \\
\text { origin }\end{array}$ & Soil type & Soil class & $\begin{array}{l}\text { Reference } \\
\text { method for } \\
\text { carbon }\end{array}$ & $\begin{array}{l}\text { Range / } \\
\text { S.D. of } \\
\text { carbon }\end{array}$ & $\begin{array}{l}\text { Drying / } \\
\text { Grinding }\end{array}$ & $\lambda$-range & $\begin{array}{l}\text { Data } \\
\text { treatment / } \\
\text { Calibration }\end{array}$ & $\begin{array}{l}\text { Cal. } \\
\text { Samples / } \\
\text { Val. } \\
\text { samples }\end{array}$ & $\mathbf{R}_{\text {val }}^{2}$ & RMSEP & Reference \\
\hline $\begin{array}{l}\text { NSW } \\
\text { Australia }\end{array}$ & $\begin{array}{l}\text { Top and } \\
\text { sub soil }\end{array}$ & $\begin{array}{l}\text { Diverse } \\
\text { orders } \\
2-72 \% \text { clay }\end{array}$ & $\begin{array}{l}\text { SOC by } \\
\text { Walkley \& } \\
\text { Black }\end{array}$ & $\begin{array}{l}0.6-49.5 / \\
8.2\end{array}$ & $\begin{array}{l}\text { Air dry / } \\
<2 \mathrm{~mm}\end{array}$ & $\begin{array}{l}400-2500 \\
\mathrm{~nm}\end{array}$ & Non / PCR & $\begin{array}{l}121 / 40 \\
\text { selected } \\
\text { from PCA } \\
\text { scores }\end{array}$ & 0.81 & 3.5 & $\begin{array}{l}\text { (Islam et al., } \\
\text { 2003) }\end{array}$ \\
\hline $\begin{array}{l}\text { Two } \\
\text { regions } \\
\text { Germany }\end{array}$ & Top soil & $\begin{array}{l}\text { Loamy sand } \\
\text { to sandy } \\
\text { loam, silty } \\
\text { clay to silty } \\
\text { loam }\end{array}$ & $\begin{array}{l}\text { SOC by } \\
\text { Dry } \\
\text { combustion } \\
600^{\circ} \mathrm{C}\end{array}$ & $\begin{array}{l}11.8-51.9 / \\
8.6 \text { and } \\
\mathrm{NA}^{*} / 5.2\end{array}$ & $\begin{array}{l}\text { Field } \\
\text { moist / <2 } \\
\text { mm }\end{array}$ & $\begin{array}{l}400-2500 \\
\mathrm{~nm}\end{array}$ & Non / PLS & $\begin{array}{l}97 \text { and } \\
67 / \mathrm{CV}\end{array}$ & $\begin{array}{l}0.88 \\
\text { and } \\
0.69\end{array}$ & $\begin{array}{l}2.9 \text { and } \\
3.7\end{array}$ & $\begin{array}{l}\text { (Udelhoven } \\
\text { et al., 2003) }\end{array}$ \\
\hline $\begin{array}{l}\text { Eastern and } \\
\text { southern } \\
\text { Africa }\end{array}$ & Top soil & $\begin{array}{l}\text { Very } \\
\text { variable } \\
5-79 \% \text { clay }\end{array}$ & $\begin{array}{l}\text { SOC by } \\
\text { dichromate } \\
\text { oxidation }\end{array}$ & $\begin{array}{l}2.3-55.8 / \\
\text { NA }\end{array}$ & $\begin{array}{l}\text { Air dry / } \\
<2 \mathrm{~mm}\end{array}$ & $\begin{array}{l}380-2460 \\
\mathrm{~nm}\end{array}$ & $\begin{array}{l}\text { Non / } \\
\text { MARS }\end{array}$ & $\begin{array}{l}674 / 337 \\
\text { random }\end{array}$ & 0.80 & 3.1 & $\begin{array}{l}\text { (Shepherd } \\
\text { and Walsh, } \\
\text { 2002) }\end{array}$ \\
\hline $\begin{array}{l}\text { Four major } \\
\text { land } \\
\text { resource } \\
\text { areas, USA }\end{array}$ & Top soil & $1-35 \%$ clay & $\begin{array}{l}\text { Total C by } \\
\text { dry } \\
\text { combustion }\end{array}$ & $\begin{array}{l}1.3-285.8 / \\
25.8\end{array}$ & $\begin{array}{l}\text { Air dry / } \\
<8 \mathrm{~mm}\end{array}$ & $\begin{array}{l}1300- \\
2500 \mathrm{~nm}\end{array}$ & $\begin{array}{l}1^{\text {st }} \\
\text { derivative / } \\
\text { PCR }\end{array}$ & $\begin{array}{l}30 \\
\text { spectrally } \\
\text { most similar } \\
\text { to val. } \\
\text { Sample/743 }\end{array}$ & 0.87 & 7.9 & $\begin{array}{l}\text { (Chang et } \\
\text { al., 2001) }\end{array}$ \\
\hline $\begin{array}{l}\text { Areas in Io } \\
\text { and Mn, } \\
\text { USA. } 5 \\
\text { soils. }\end{array}$ & Top soil & $\begin{array}{l}\text { Silty clay } \\
\text { loam and } \\
\text { Silt loam }\end{array}$ & $\begin{array}{l}\text { SOC by } \\
\text { carbonate } \\
\text { corrected dry } \\
\text { combustion }\end{array}$ & $\begin{array}{l}15.4-144.9 \\
/ 26.1\end{array}$ & $\begin{array}{l}\text { Oven dry / } \\
<2 \mathrm{~mm} \\
\text { crushed in } \\
\text { agate } \\
\text { mortar }\end{array}$ & $\begin{array}{l}400-2500 \\
\mathrm{~nm}\end{array}$ & $\begin{array}{l}1^{\text {st }} \\
\text { derivative / } \\
\text { PLS }\end{array}$ & $\begin{array}{l}76 / 32 \\
\text { random }\end{array}$ & 0.89 & 6.2 & $\begin{array}{l}\text { (Chang and } \\
\text { Laird, 2002) }\end{array}$ \\
\hline $\begin{array}{l}\text { Five Io soil } \\
\text { series }\end{array}$ & $\begin{array}{l}\text { Increment } \\
\text { soil cores } \\
\text { to } 38-108 \\
\mathrm{~cm}\end{array}$ & $4-43 \%$ clay & $\begin{array}{l}\text { SOC by } \\
\text { carbonate } \\
\text { corrected dry } \\
\text { combustion }\end{array}$ & $\begin{array}{l}0.5-40.8 / \\
10.4\end{array}$ & $\begin{array}{l}\text { Air dry / } \\
<2 \mathrm{~mm}\end{array}$ & $\begin{array}{l}1100- \\
2500 \mathrm{~nm}\end{array}$ & $\begin{array}{l}1^{\text {st }} \\
\text { derivative / } \\
\text { PLS }\end{array}$ & $\begin{array}{l}161 \text { (seven } \\
\text { sites)/ } 83 \\
\text { (three sites) }\end{array}$ & 0.88 & 3.8 & $\begin{array}{l}\text { (Chang et } \\
\text { al., 2005) }\end{array}$ \\
\hline
\end{tabular}




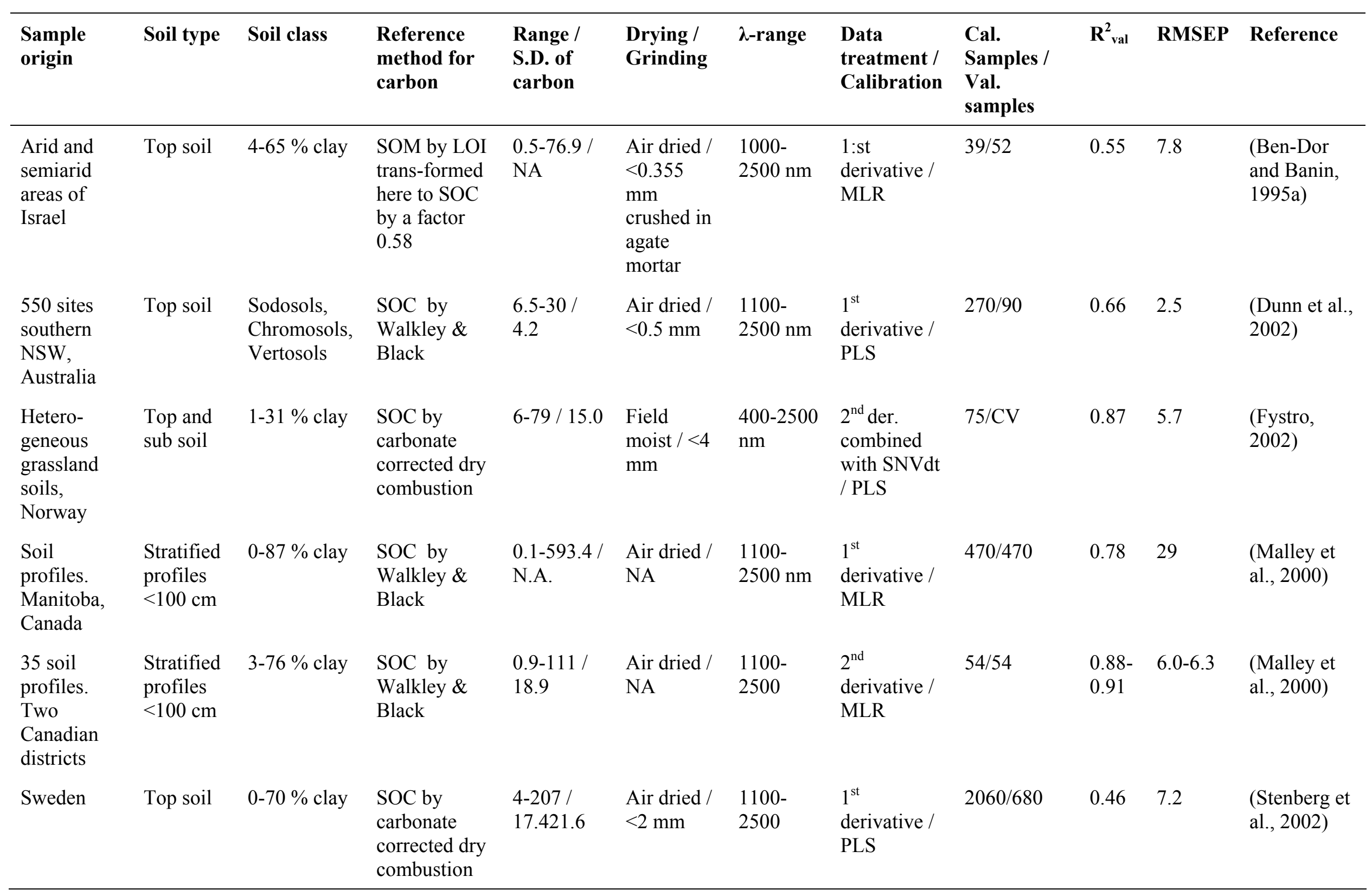




\begin{tabular}{|c|c|c|c|c|c|c|c|c|c|c|c|}
\hline $\begin{array}{l}\text { Sample } \\
\text { origin }\end{array}$ & Soil type & Soil class & $\begin{array}{l}\text { Reference } \\
\text { method for } \\
\text { carbon }\end{array}$ & $\begin{array}{l}\text { Range / } \\
\text { S.D. of } \\
\text { carbon }\end{array}$ & $\begin{array}{l}\text { Drying / } \\
\text { Grinding }\end{array}$ & $\lambda$-range & $\begin{array}{l}\text { Data } \\
\text { treatment / } \\
\text { Calibration }\end{array}$ & $\begin{array}{l}\text { Cal. } \\
\text { Samples / } \\
\text { Val. } \\
\text { samples }\end{array}$ & $\mathbf{R}_{\text {val }}^{2}$ & RMSE & Reference \\
\hline Denmark & Top soil & $2-74 \%$ clay & $\begin{array}{l}\text { Total C by } \\
\text { dry } \\
\text { combustion }\end{array}$ & $\begin{array}{l}0.6-56 / \\
10.1\end{array}$ & $\begin{array}{l}55^{\circ} \mathrm{C} /<2 \\
\mathrm{~mm}\end{array}$ & $408-2492$ & $\begin{array}{l}1^{\text {st }} \\
\text { derivative / } \\
\text { PLS }\end{array}$ & $690 / 139$ & 0.66 & 4.2 & $\begin{array}{l}\text { (Sorensen } \\
\text { and } \\
\text { Dalsgaard, } \\
2005 \text { ) }\end{array}$ \\
\hline Uruguay & Top soil & $8-52 \%$ clay & $\begin{array}{l}\text { SOC by } \\
\text { dichromatic } \\
\text { oxidation }\end{array}$ & $\begin{array}{l}10.3-68.5 / \\
15.0\end{array}$ & $\begin{array}{l}40^{\circ} \mathrm{C} /<2 \\
\mathrm{~mm}\end{array}$ & $400-2500$ & $\begin{array}{l}1^{\text {st }} \\
\text { derivative / } \\
\text { PLS }\end{array}$ & $177 / 139$ & 0.74 & 5.0 & $\begin{array}{l}\text { (Moron and } \\
\text { Cozzolino, } \\
\text { 2002) }\end{array}$ \\
\hline $\begin{array}{l}\text { Global } \\
\text { (90\% from } \\
\text { the USA) }\end{array}$ & Profiles & $1-93 \%$ clay & $\begin{array}{l}\text { SOC by } \\
\text { Walkley \& } \\
\text { Black }\end{array}$ & $\begin{array}{l}0-242 / \\
\text { NA }\end{array}$ & $\begin{array}{l}\text { Air dried / } \\
<2 \mathrm{~mm}\end{array}$ & $350-2500$ & $\begin{array}{l}1^{\text {st }} \\
\text { derivative / } \\
\text { Boosted } \\
\text { regression } \\
\text { trees }\end{array}$ & $\begin{array}{l}4184 / \mathrm{CV} \text { in } \\
6 \text { segments }\end{array}$ & 0.82 & 9.0 & $\begin{array}{l}\text { (Brown et } \\
\text { al., 2006) }\end{array}$ \\
\hline Brazil & $\begin{array}{l}\text { Not } \\
\text { specified }\end{array}$ & $\begin{array}{l}\text { Oxisols and } \\
\text { Ultiols }\end{array}$ & $\begin{array}{l}\text { SOC by } \\
\text { dichromatic } \\
\text { oxidation }\end{array}$ & $\begin{array}{l}4.0-48.8 / \\
\text { NA }\end{array}$ & $\begin{array}{l}40^{\circ} \mathrm{C} / \\
<0.177 \\
\mathrm{~mm}\end{array}$ & $\begin{array}{l}1000- \\
2500 \mathrm{~nm}\end{array}$ & $\begin{array}{l}2^{\text {nd }} \\
\text { derivative / } \\
\text { Neural } \\
\text { networks on } \\
\text { PCA scores }\end{array}$ & $140 / 60$ & 0.92 & 2.5 & $\begin{array}{l}\text { (Fidencio et } \\
\text { al., 2002a) }\end{array}$ \\
\hline $\begin{array}{l}\text { Flemish } \\
\text { part of } \\
\text { Belgium }\end{array}$ & Top soil & $\begin{array}{l}\text { Very } \\
\text { variable }\end{array}$ & $\begin{array}{l}\text { SOC by } \\
\text { Walkley \& } \\
\text { Black }\end{array}$ & $\begin{array}{l}0.77-60 \\
/ 9.5\end{array}$ & $\begin{array}{l}\text { Field } \\
\text { moist / <2 } \\
\text { mm }\end{array}$ & $\begin{array}{l}300- \\
1700\end{array}$ & $\begin{array}{l}1^{\text {st }} \\
\text { derivative } \\
\text { after MSC / } \\
\text { PLS }\end{array}$ & $306 / 50$ & 0.74 & 4.8 & $\begin{array}{l}\text { (Mouazen et } \\
\text { al., 2007) }\end{array}$ \\
\hline
\end{tabular}


to $4 \%$ SOM (presumably $20-25 \mathrm{mg} \mathrm{g}^{-1} \mathrm{C}$ ) the organic material consisted mostly of humic substances while in another group of soils with more than 4\% SOM it consisted mostly of decomposed litter, which can be expected to vary more than well-decomposed humus. This may be the case if the accumulation of SOM is due to impeded degradation as a result of, for example, very dry or excessively wet conditions. Contradictorily, Stenberg et al. (1998) found the organic matter present in high yielding agricultural soils with little SOM to be more susceptible to microbial degradation, which suggests that the given explanation is not universal. Nevertheless, Martin et al. (2002) found that in Manitoba, values for agricultural soils ranging between 3.8 and $40 \mathrm{mg} \mathrm{g}^{-1} \mathrm{C}$ tended to be under-predicted at both the lower and higher ends, while mid-range values tended to be over predicted. By thresholding the data at $20 \mathrm{mg} \mathrm{g}^{-1} \mathrm{C}$, two equally sized data sets with similar standard deviations, residual mean squared error (RMSE) values of 4 and $4.3 \mathrm{mg} \mathrm{g}^{-1} \mathrm{C}$, were obtained. The RMSE for the low range set was reduced by $40 \%$ compared with that for all samples, while the RMSE for the high range set was hardly affected.

Another point to consider is that random sample sets dealing with organic matter in agricultural soils can be expected to reflect the natural skewness of the data towards low values. This skewness would be more pronounced in data sets with large variation and wider range. A small number of large values would also explain the largest correlation coefficients being found in data sets with the largest standard deviations (Fig. 3B).

Data sets with large variation in SOM may also be expected to originate from larger geographical regions with more variable soil, although this is not supported by the data in Table 2. Nevertheless, using a large data set representative of Swedish agricultural soils, Stenberg et al. (2002) found that calibrations for organic matter could be substantially improved by removing the sandiest soils (Fig. 4) and that it was not possible to make an accurate calibration for the entire data set (RMSE 1/4 $7.2 \mathrm{mg} \mathrm{g}^{-1}$ SOC). The authors was postulated that sandy soils caused scattering of light (due to quartz), and 'masked' absorptions of organic matter. Another possible but contradictory explanation may be that SOC in very sandy soils is over estimated as the organic matter is the stronger absorbent in the matrix and will therefore dominate the spectra (Clark, 1999; see the visible end of Fig. 2a). Also the smaller surface area of coarse sandy soils will influence as the same amount of organic matter will be distributed in thicker coatings. Stenberg (2010) observed that predictions of SOC had larger errors. When the soils contained larger amounts of sand and that the errors in the sandiest soils were clearly dominated by over estimations.
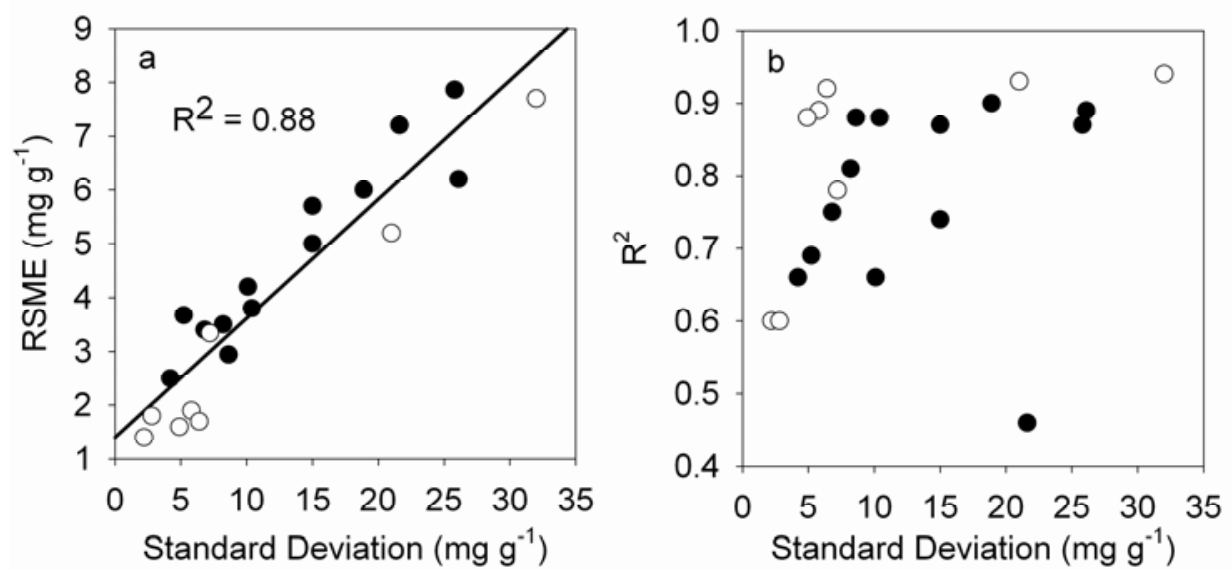

Figure 3. Published data on organic carbon predictions with vis-NIR spectroscopy. Correlations between the standard deviation and (A) RMSE and (B) R2. (d) Data extracted from publications given in Table 2 and (O) data extracted from (Martin et al., 2002; McCarty and Reeves, 2006; Udelhoven et al., 2003;

Viscarra Rossel et al., 2006c; Wetterlind et al., 2008a,b). 
It is often suggested that smaller soil variation at the field scale would result in better calibrations than more general ones over larger geographic areas. Accordingly reported RMSE values are in several field or farm scale studies as low as or lower than $2 \mathrm{mg} \mathrm{g}^{-1}$ (McCarty and Reeves, 2006; Udelhoven et al., 2003; Viscarra Rossel et al., 2006c; Wetterlind et al., 2008a). There is also an obvious tendency in Fig. 3A that large scale calibrations are found above the regression line while field scale calibrations are found below, indicating slightly better predictions of field scale calibrations. Therefore, there is support for a general rule that overall soil variation would influence prediction performance, but only to a small extent. The reason that field- or farm-scale calibrations perform generally better than calibrations made at regional or coarser scales might be that the variation in SOM is also small at the finer spatial scales (Fig. 3). There are also examples of field-specific calibrations with high RMSE values between 3.3 and $7.7 \mathrm{mg} \mathrm{g}^{-1}$, but with high $\mathrm{R}^{2}$ values (Martin et al., 2002; Wetterlind et al., 2008a). Field-scale studies of both large and small RMSE values fit well in both scatter plots in Fig. 3. This indicates that the variation in SOM itself is the key factor.

Unfortunately there are few examples of data sets with very high OM. The exceptions are Ludwig et al (2002), Chodak et al. (2002), and Couteaux et al. (2003), reporting on two Eucalyptus sites in Australia, three spruce and birch sites in Germany and five coniferous sites in Sweden and France, respectively. Their results from data sets ranging between 255 and $500 \mathrm{mg} \mathrm{C} \mathrm{g \_ 1} \mathrm{show} \mathrm{that} \mathrm{in} \mathrm{all} \mathrm{three} \mathrm{cases} \mathrm{R2} \mathrm{values}$ were greater than 0.96, although the RMSE values were high, ranging between 14 and $24 \mathrm{mg}$ g_1. Although standard deviations were not reported, we estimated standard deviations from graphically displayed data to be within a 50-150 mg g_1 range, supporting the general principle indicated by Fig. 3 .

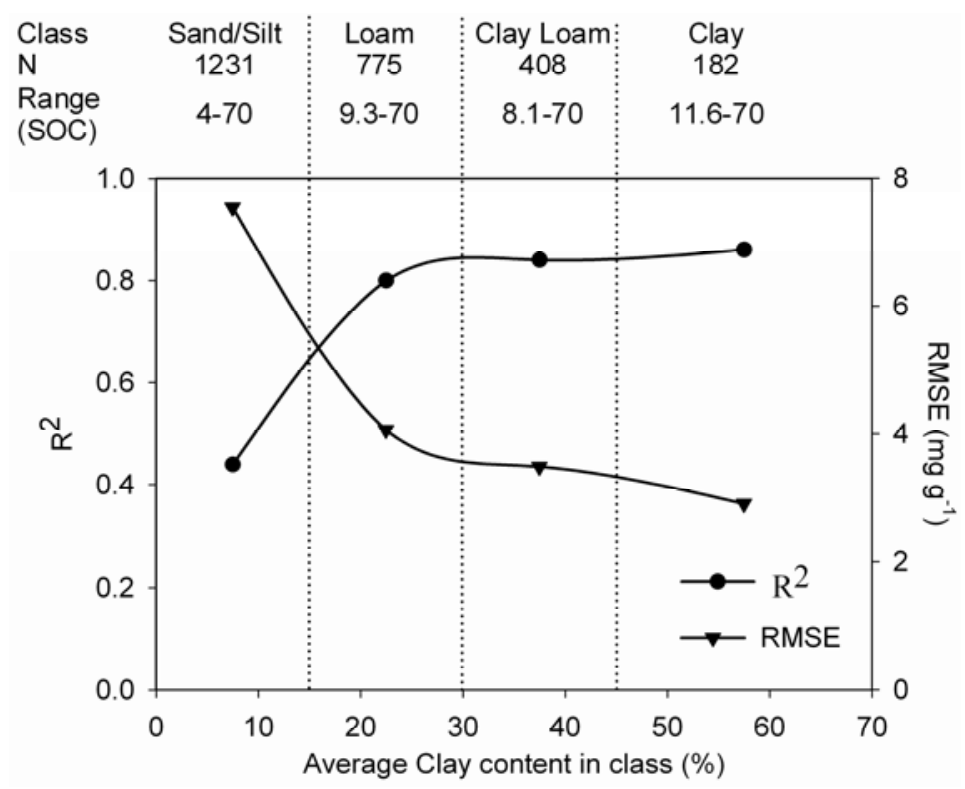

Figure 4. Differences in calibration performance for soil organic carbon (SOC) between different texture classes (from Stenberg et al., 2002).

Whether the nitrogen content in soil is predicted through autocorrelation to organic carbon or on the basis of specific absorption is debatable. Published results are not consistent. Vis-NIR calibrations for total or organic $\mathrm{N}$ rarely perform better than the corresponding calibration for SOM or SOC (Viscarra Rossel et al. 2006c). Nevertheless, organic $\mathrm{N}$ has specific overtone and combination absorptions in the vis-NIR region (Table 1) and there are reports suggesting that organic $\mathrm{C}$ and $\mathrm{N}$ are predicted independently by vis-NIR. For example, organic and inorganic $\mathrm{C}$ and soil $\mathrm{N}$ was made to vary independently through artificial 
addition of $\mathrm{CaCO} 3$, various composts and humic acid and all three constituents were shown to be predicted through unique spectral signatures (Chang and Laird, 2002).

However, it is indisputable that the nitrogen content in soil is almost as related to the organic matter content as organic carbon, as the absolute majority of the $\mathrm{N}$ is organic and typically comprises about $1 / 10$ of the organic $\mathrm{C}$. Thus, the $\mathrm{N}$ content is also very low, generally well below $1 \%$ and $\mathrm{N}$-specific absorptions in the vis-NIR would be expected to be very weak. In a set of heterogeneous Norwegian grassland soils, the $\mathrm{R}^{2}$ for vis-NIR-predicted organic $\mathrm{C}$ and total $\mathrm{N}$ was 0.87 and 0.80 , respectively, while the $\mathrm{R}^{2}$ between organic $\mathrm{C}$ and total $\mathrm{N}$ was 0.65 (Fystro, 2002). In fact, loss of ignition (Fystro, 2002) had the same predictive capacity as vis-NIR for both $\mathrm{C}$ and $\mathrm{N}$. In this data set the correlation spectra, formed by the correlation of individual bands, to $\mathrm{C}$ and $\mathrm{N}$, respectively, had similar general features, but there were variations in peak heights.

One way to test the potential independence between predictions of $\mathrm{C}$ and $\mathrm{N}$ would be to make calibrations for the C:N ratio. In artificially constructed soils (Chang and Laird, 2002) such a prediction worked fairly well $\left(\mathrm{R}^{2}=0.85\right)$. In contrast, at an agricultural Manitoba site $\mathrm{N}$ calibrations were much less satisfactory than the corresponding $\mathrm{C}$ calibrations and $\mathrm{C}: \mathrm{N}$ ratio calibrations failed as the correlation between $\mathrm{C}$ and $\mathrm{N}$ was only 0.67 , while the correlation between predicted $\mathrm{C}$ and $\mathrm{N}$ was as high as 0.96 (Martin et al., 2002). These authors suggested, that $\mathrm{N}$ is best predicted when $\mathrm{N}$ is well correlated to $\mathrm{C}$, but in the absence of such correlation, calibrations may be based on $\mathrm{N}$-specific absorbing features.

\subsection{Soil mineralogy}

Soil minerals generally account for half the soil volume (Schulze, 2002). Their type, proportions and concentrations ultimately determine important properties such as texture, structure, and CEC. These properties may in turn have a significant effect on many other soil properties. For example, potassium availability for plant uptake is dependent on its release from the weathering of primary soil minerals. Soil minerals absorb light in the UV, visible, vis-NIR, and mid-IR portions of the electromagnetic spectrum. Iron oxides absorb strongly in the UV and absorb weakly in the vis-NIR region, while clay minerals such as phyllosilicates have distinct spectral signatures in the vis-NIR region. Comprehensive accounts of the processes that produce these absorptions can be found in Hunt (1977), Clark (1999), etc. In this review, we concentrate on diagnostic absorption for the most commonly encountered iron oxides (goethite, haematite) and clay minerals (kaolin, montmorillonite (smectite), illite, and calcite). Figure 5 shows the continuum-removed reflectance spectra of these minerals.

The reflectivity of goethite $(\alpha-\mathrm{FeOOH})$ is relatively high at longer wavelengths in the vis-NIR region from the absorption band that occurs near $930 \mathrm{~nm}$ (Fig. 5). Three other absorption bands for goethite are discernible in the vis-NIR region, one near $660 \mathrm{~nm}$, another near $480 \mathrm{~nm}$ and one near $420 \mathrm{~nm}$ (Fig. 5). The spectrum of goethite also shows weak absorption near $1700 \mathrm{~nm}$, which is due to the first overtone of a stretching vibration of $\mathrm{OH}$ that is present in the crystal structure of goethite (Morris et al., 1985). The spectrum of haematite $(\alpha-\mathrm{Fe} 2 \mathrm{O} 3)$ is characterized by high and nearly constant reflectivity at longer wavelengths in the vis-NIR, a reflectivity minimum near $880 \mathrm{~nm}$, a shoulder centered near $620 \mathrm{~nm}$ and a band with very low reflectivity near $510 \mathrm{~nm}$ (Fig. 5).

In both goethite and haematite the absorptions near 930 and $880 \mathrm{~nm}$, respectively, may be assigned to ligand field transitions that involve excitations from a ground state to the first higher energy state (Sherman and Waite, 1985). Their absorptions near $660 \mathrm{~nm}$ and the shoulder near $620 \mathrm{~nm}$ may also be assigned to charge transfer absorptions producing transitions from a ground state to a higher energy state. Assignment of bands near $480 \mathrm{~nm}$ and $420 \mathrm{~nm}$ in goethite and near $510 \mathrm{~nm}$ in haematite are generally attributed to the absorption edges (or wings) of intense charge transfer absorptions that occur in the UV (Sherman and Waite, 1985). Absorption in the visible range causes the vivid colors of iron oxides, for example, red haematite and yellow goethite. 


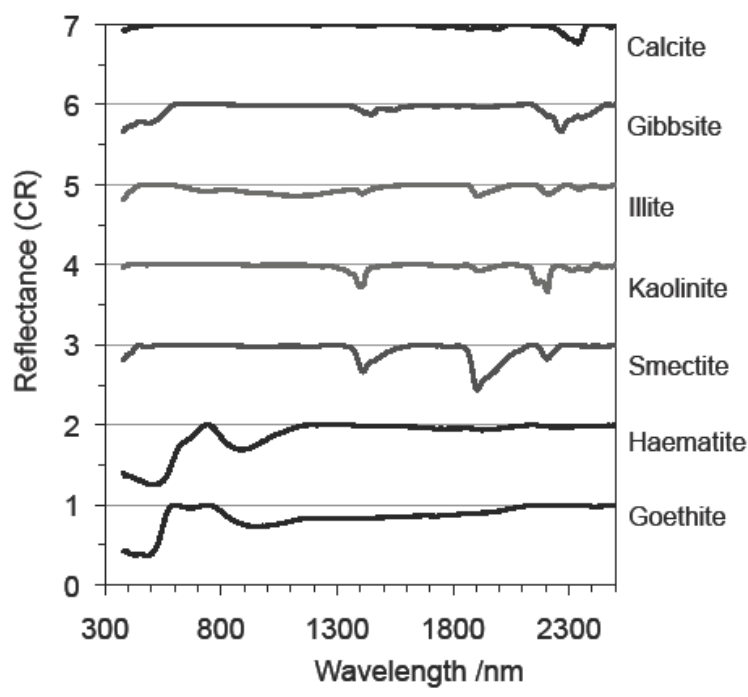

Figure 5. Continuum-removed spectra of common soil minerals offset by 1 unit for each spectrum.

Combination vibrations involving a $\mathrm{O}-\mathrm{H}$ stretch and metal-OH bend occur in the 2200-2500 nm region. It is generally understood that absorptions near $2200 \mathrm{~nm}$ are due to $\mathrm{Al}-\mathrm{OH}$, as in kaolinite, montmorillonite, and illite (Fig. 5), but if the absorption is near $2290 \mathrm{~nm}$ it is due to $\mathrm{Fe}-\mathrm{OH}$ and if near $2300 \mathrm{~nm}$ it is due to $\mathrm{Mg}-\mathrm{OH}$ in, for example, illites and montmorillonites (Clark et al., 1990; Post and Noble, 1993). There are exceptions to this, for example in gibbsite (AlOH3) the combination absorption occurs near $2268 \mathrm{~nm}$ instead of $2200 \mathrm{~nm}$.

Clay mineral absorptions are mostly due to $\mathrm{OH}, \mathrm{H} 2 \mathrm{O}$, and $\mathrm{CO} 3$ overtones and combination vibrations of fundamentals that occur at longer wavelengths in the mid-IR region. Kaolin has characteristic absorption doublets near $2200 \mathrm{~nm}$ and $1400 \mathrm{~nm}$ (Fig. 5). The absorption wavelengths near $1400 \mathrm{~nm}$ (1395 and 1415 $\mathrm{nm})$ are due to overtones of the $\mathrm{O}-\mathrm{H}$ stretch vibration near $2778 \mathrm{~nm}\left(3600 \mathrm{~cm}^{-1}\right)$, while those near 2200 $\mathrm{nm}(2165$ and $2207 \mathrm{~nm})$ are due to $\mathrm{Al}-\mathrm{OH}$ bend plus $\mathrm{O}-\mathrm{H}$ stretch combinations.

Smectite has strong characteristic absorptions near 1400, 1900, and $2200 \mathrm{~nm}$. The band near $1400 \mathrm{~nm}$ can to one part be attributed to the first overtone of structural $\mathrm{O}-\mathrm{H}$ stretching mode in its octahedral layer. The $1400 \mathrm{~nm}$ and $1900 \mathrm{~nm}$ bands are also due to combination vibrations of water bound in the interlayer lattices as hydrated cations and water adsorbed on particle surfaces (Bishop et al., 1994). Such water is not present in kaoline supporting a diagnostic feature for dry kaolinitic soils that will absorb very weakly near $1900 \mathrm{~nm}$. The combination bands that are due to vibrations of bound water occur at slightly shorter wavelengths near $1400 \mathrm{~nm}$ and $1900 \mathrm{~nm}$, while those of adsorbed water appear as shoulders near $1468 \mathrm{~nm}$ and $1970 \mathrm{~nm}$ (Fig. 5). By remoistening, these shoulders will dominate (Bishop et al., 1994). Illite has absorptions near 1400, 1900, and $2200 \mathrm{~nm}$ too, but generally weaker than smectite. Illite also has additional absorptions near $2340 \mathrm{~nm}$ and $2445 \mathrm{~nm}$ (Post and Noble, 1993) (Fig. 5). These bands may diagnostically distinguish between illite and smectite. They are, however, weak and especially the former may be confused with organic matter absorption.

Carbonates have several absorptions in the NIR region, which are due to overtone and combination bands of the CO3 fundamental that occurs in mid-IR (Clark et al., 1990). The strongest is near $2335 \mathrm{~nm}$, but some weaker absorptions occur near $2160 \mathrm{~nm}, 1990 \mathrm{~nm}$ and $1870 \mathrm{~nm}$ (Fig. 5). There is also strong absorption right at the edge of the NIR-region near $2500 \mathrm{~nm}$ (Clark, 1999). It is important to note that the position of these absorption bands varies with composition (Hunt and Salisbury, 1970). Although there are studies that qualitatively characterize soil minerals using diffuse reflectance spectroscopy (Clark et al., 1990; Farmer, 1974; Hunt, 1977; Hunt and Salisbury, 1970), few studies quantify their composition in 
soil. Ben-Dor and Banin (1990) used vis-NIR to estimate the carbonate concentration in soils. Ben-Dor and Banin (1994) used NIR (400-1100 nm) to estimate $\mathrm{CaCO} 3, \mathrm{Fe} 2 \mathrm{O} 3, \mathrm{Al} 2 \mathrm{O} 3, \mathrm{SiO} 2$, free Fe oxides and K2O. Brown et al. (2006) attempted predictions of ordinal clay mineral levels (0-5 ordinal scale) of kaolinite, smectite, and vermiculite to $96 \%, 88 \%$, and $83 \%$ respectively, falling within one ordinal unit of reference X-ray diffraction (XRD) values. Viscarra Rossel et al. (2006a) modeled mineral-organic mixes as a function of vis-NIR spectra to estimate mineral-organic composition of independent test mixes. Viscarra Rossel et al. (2009) made accurate measurements of soil mineral composition and clay content using field collected spectra.

\subsection{Soil texture}

When it comes to soil texture, most focus has been on clay content because it has a large influence on structure by promoting the formation of soil aggregates and its swelling and shrinking properties forming cracks. Water dynamics and aeration in soil are highly dependent on texture and structure and the latter are therefore important for plant growth both directly, but also through the regulation of microorganisms the engine in decomposition and nutrient cycling processes (Stenberg, 1999). There are also environmental aspects, as structure influences the risk of nutrient and pesticide leaching (Jarvis, 2007; Stenberg et al., 1999). Although clay is defined as particles smaller than $2 \mathrm{~mm}$, clay particles mainly consist of clay minerals. Therefore the influence of mineralogy on vis-NIR spectra can be assumed to be a valuable feature for predictions of clay content. Ben-Dor and Banin (1995a) found the important bands for calibrations of clay content and the related parameters specific surface area (SSA) and CEC, to be related to both $\mathrm{O}-\mathrm{H}$ in water and $\mathrm{Mg}-, \mathrm{Al}-$, and $\mathrm{Fe}-\mathrm{OH}$ in the mineral crystal lattice. These bands are similar to those reported by Madejova and Komadel (2001) to distinguish different clay minerals.

As SSA and CEC are better defined and more directly related to particle size distribution and mineralogy than clay content, simply defined as particles smaller than $2 \mathrm{~mm}$, it could be expected that these parameters would also be better predicted through vis-NIR calibrations. This is indeed often the case (Ben-Dor and Banin, 1995a; Brown et al., 2006; Chang et al., 2001; Shepherd and Walsh, 2002), although in Australian soils calibrations for CEC performed poorly compared to clay (Islam et al., 2003; Viscarra Rossel et al., 2006c). Compared with calibrations for sand and silt content, those for clay usually perform well over large geographical regions (Chang et al., 2001; Islam et al., 2003; Malley et al., 2000; Shepherd and Walsh, 2002; Sörensen and Dalsgaard, 2005).Here, RMSE values averaged 10.6\%, 7.4\%, and 5.7\% for sand, silt, and clay, respectively and the ratio of standard deviation/RMSE (RPD; not available for Shepherd and Walsh, 2002) averaged 1.9, 1.6, and 1.8 (Table 3). Although Chang et al. (2001) classified calibrations for sand and silt as better performing than for clay based on correlation coefficients and RPD values, the absolute RMSE was less than half for clay, which can be attributed to the clay content range also being less than half. Unfortunately no one has yet published the accuracy of soil classification from vis-NIR-predicted sand, silt and clay. However, directly on vis-NIR spectra Mouazen et al. (2005b) used a combination of principal component and factorial discriminant analyses to classify 365 soil samples from Belgium and Northern France into different texture groups. In a validation procedure, $81.8 \%$ were correctly classified into the four groups coarse sandy, fine sandy, loamy, and clayey or $85.1 \%$ into the three groups sandy, loamy, and clayey soils. 


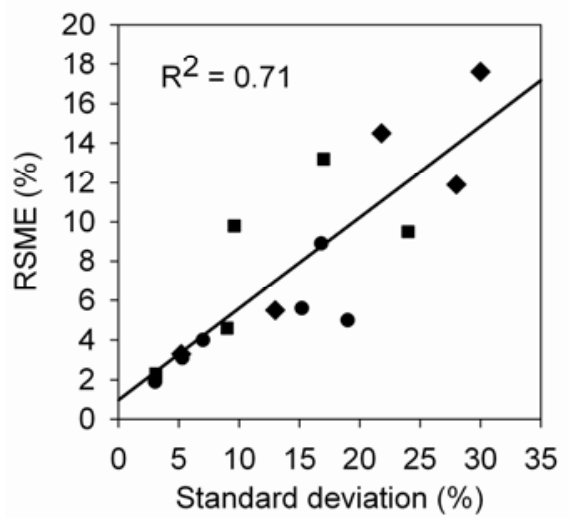

Figure 6. Literature data on clay (d), silt (j), and sand (r) predictions with vis-NIR spectroscopy. Correlations between the standard deviation and the RMSE. Data extracted from (Chang et al., 2001;

Islam et al., 2003; Malley et al., 2000; Shepherd and Walsh, 2002; S_rensen and Dalsgaard, 2005;

Stenberg et al., 2002; Viscarra Rossel et al., 2006c).

As for SOC there were obvious relationships in published data between RSME and variation in the reference texture parameters (Fig. 6). The influence of this relationship may have been in line with what Stenberg et al. (2002) found. The RMSE of a NIR calibration for clay content for all agricultural areas of Sweden was reduced from $5.6 \%$ to $3.9 \%$ clay by dividing the data set according to six geographical zones using separate calibrations for each zone instead of using one calibration for all samples. By doing so, several very bad predictions were corrected and an obvious under-estimation of samples over $30 \%$ clay was removed. In this case the limitation of geological heterogeneity in each subset was probably an important factor.

There is no evidence of RMSE values much lower than $2 \%$ in studies limited to even smaller regional, farm or field scale calibrations (Malley et al., 2000; Viscarra Rossel et al., 2006c; Waiser et al., 2007; Wetterlind et al., 2008a,b), although in these cases RMSE values were among the lowest published (Table 3 ) and RPD values usually higher than 2 and in some cases close to three 3 .

Table 3. Validation results for soil texture parameters clay, silt and sand ( \%).

\begin{tabular}{|c|c|c|c|c|c|c|c|}
\hline Origin & $\begin{array}{l}\text { Soil } \\
\text { information }\end{array}$ & Range & S.D. & $\begin{array}{l}\text { Spectral } \\
\text { range }\end{array}$ & $\begin{array}{l}\text { Validation } \\
\mathbf{R}^{\mathbf{2}}\end{array}$ & $\begin{array}{l}\text { Validation } \\
\text { RMSE }\end{array}$ & Reference \\
\hline \multicolumn{8}{|l|}{ Clay } \\
\hline $\begin{array}{l}\text { Israel; Arid } \\
\text { and semi- } \\
\text { arid }\end{array}$ & $\mathrm{A}_{0}$-horizon & $4-65$ & $\mathrm{NA}^{*}$ & $1000-2500 \mathrm{~nm}$ & 0.56 & 10.3 & $\begin{array}{l}\text { (Ben-Dor } \\
\text { and Banin, } \\
\text { 1995a) }\end{array}$ \\
\hline $\begin{array}{l}\text { Global }(90 \% \\
\text { from the } \\
\text { USA) }\end{array}$ & Profiles & $1-93$ & NA & $350-2500 \mathrm{~nm}$ & 0.73 & 9.5 & $\begin{array}{l}\text { (Brown et } \\
\text { al., 2006) }\end{array}$ \\
\hline $\begin{array}{l}\text { USA; Four } \\
\text { major land } \\
\text { resource } \\
\text { areas }\end{array}$ & Top soil & $1-35$ & 7 & $1300-2500 \mathrm{~nm}$ & 0.67 & 4.1 & $\begin{array}{l}\text { (Chang et } \\
\text { al., 2001) }\end{array}$ \\
\hline Eastern and & Top soil & $5-79$ & NA & $350-2500 \mathrm{~nm}$ & 0.78 & 7.5 & (Shepherd \\
\hline
\end{tabular}




\begin{tabular}{|c|c|c|c|c|c|c|c|}
\hline Origin & $\begin{array}{l}\text { Soil } \\
\text { information }\end{array}$ & Range & S.D. & $\begin{array}{l}\text { Spectral } \\
\text { range }\end{array}$ & $\begin{array}{l}\text { Validation } \\
\mathbf{R}^{2}\end{array}$ & $\begin{array}{l}\text { Validation } \\
\text { RMSE }\end{array}$ & Reference \\
\hline $\begin{array}{l}\text { southern } \\
\text { Africa }\end{array}$ & & & & & & & $\begin{array}{l}\text { and Walsh, } \\
\text { 2002) }\end{array}$ \\
\hline $\begin{array}{l}\text { NSW } \\
\text { Australia }\end{array}$ & $\begin{array}{l}\text { Top and sub } \\
\text { soil }\end{array}$ & $2-72$ & 19 & $250-2500 \mathrm{~nm}$ & 0.72 & 8.9 & $\begin{array}{l}\text { (Islam et al., } \\
\text { 2003) }\end{array}$ \\
\hline $\begin{array}{l}\text { NSW } \\
\text { Australia; } 17 \\
\text { ha field }\end{array}$ & Top soil & $8-24$ & 3 & $1000-2500 \mathrm{~nm}$ & 0.60 & 1.9 & $\begin{array}{l}\text { (Viscarra } \\
\text { Rossel et al., } \\
\text { 2006b) }\end{array}$ \\
\hline $\begin{array}{l}\text { Canadian } \\
\text { district }\end{array}$ & Profiles & $1-87$ & NA & $1100-2498 \mathrm{~nm}$ & 0.81 & 8.6 & $\begin{array}{l}\text { (Malley et } \\
\text { al., 2000) }\end{array}$ \\
\hline $\begin{array}{l}\text { Swedish } \\
\text { agriculture }\end{array}$ & Top soil & $0-70$ & 15 & $1100-2500$ & 0.94 & 3.9 & $\begin{array}{l}\text { (Stenberg et } \\
\text { al. 2002) }\end{array}$ \\
\hline $\begin{array}{l}\text { Texas, USA; } \\
\text { Six fields }\end{array}$ & Profiles & $1-52$ & 14 & $350-2500 \mathrm{~nm}$ & 0.84 & 6.2 & $\begin{array}{l}\text { (Waiser et } \\
\text { al. 2007) }\end{array}$ \\
\hline $\begin{array}{l}\text { Sweden; } \\
\text { Tree } \\
\text { separate } \\
\text { fields 11-25 } \\
\text { ha }\end{array}$ & Top soil & $\begin{array}{l}12-62 \\
8-37 \\
23-52\end{array}$ & $\begin{array}{l}11 \\
6 \\
8\end{array}$ & $780-2500 \mathrm{~nm}$ & $\begin{array}{l}0.86 \\
0.81 \\
0.47\end{array}$ & $\begin{array}{l}3.9 \\
2.8 \\
5.7\end{array}$ & $\begin{array}{l}\text { (Wetterlind } \\
\text { et al. 2008a) }\end{array}$ \\
\hline $\begin{array}{l}\text { Swedish } \\
\text { farm; } \\
\sim 100 \text { ha }\end{array}$ & Top soil & $25-66$ & 9 & $350-2500 \mathrm{~nm}$ & 0.81 & 3.7 & $\begin{array}{l}\text { (Wetterlind } \\
\text { et al. 2008b) }\end{array}$ \\
\hline \multicolumn{8}{|l|}{ Silt } \\
\hline $\begin{array}{l}\text { USA; Four } \\
\text { major land } \\
\text { resource } \\
\text { areas }\end{array}$ & Top soil & $3-85$ & 24 & $1300-2500 \mathrm{~nm}$ & 0.84 & 9.5 & $\begin{array}{l}\text { (Chang et } \\
\text { al., 2001) }\end{array}$ \\
\hline $\begin{array}{l}\text { Eastern and } \\
\text { southern } \\
\text { Africa }\end{array}$ & Top soil & $0-42$ & NA & $350-2500 \mathrm{~nm}$ & 0.67 & 4.9 & $\begin{array}{l}\text { (Shepherd } \\
\text { and Walsh, } \\
\text { 2002) }\end{array}$ \\
\hline $\begin{array}{l}\text { NSW } \\
\text { Australia }\end{array}$ & $\begin{array}{l}\text { Top and sub } \\
\text { soil }\end{array}$ & $0-40$ & 9 & $250-2500 \mathrm{~nm}$ & 0.05 & 9.8 & $\begin{array}{l}\text { (Islam et al., } \\
\text { 2003) }\end{array}$ \\
\hline $\begin{array}{l}\text { NSW } \\
\text { Australia; } 17 \\
\text { ha field }\end{array}$ & Top soil & $6-20$ & 3 & $1000-2500 \mathrm{~nm}$ & 0.41 & 2.3 & $\begin{array}{l}\text { (Viscarra } \\
\text { Rossel et al., } \\
\text { 2006b) }\end{array}$ \\
\hline $\begin{array}{l}\text { Canadian } \\
\text { districts }\end{array}$ & Profiles & $1-76$ & NA & $1100-2498 \mathrm{~nm}$ & 0.36 & 13.2 & $\begin{array}{l}\text { (Malley et } \\
\text { al., 2000) }\end{array}$ \\
\hline Sand & & & & & & & \\
\hline
\end{tabular}




\begin{tabular}{|c|c|c|c|c|c|c|c|}
\hline Origin & $\begin{array}{l}\text { Soil } \\
\text { information }\end{array}$ & Range & S.D. & $\begin{array}{l}\text { Spectral } \\
\text { range }\end{array}$ & $\begin{array}{l}\text { Validation } \\
\mathbf{R}^{2}\end{array}$ & $\begin{array}{l}\text { Validation } \\
\text { RMSE }\end{array}$ & Reference \\
\hline $\begin{array}{l}\text { Global }(90 \% \\
\text { from the } \\
\text { USA })\end{array}$ & Profiles & $1-99$ & NA & $350-2500 \mathrm{~nm}$ & 0.57 & 17.6 & $\begin{array}{l}\text { (Brown et } \\
\text { al., 2006) }\end{array}$ \\
\hline $\begin{array}{l}\text { USA; Four } \\
\text { major land } \\
\text { resource } \\
\text { areas }\end{array}$ & Top soil & $1-95$ & 28 & $1300-2500 \mathrm{~nm}$ & 0.82 & 11.9 & $\begin{array}{l}\text { (Chang et } \\
\text { al., 2001) }\end{array}$ \\
\hline $\begin{array}{l}\text { Eastern and } \\
\text { southern } \\
\text { Africa }\end{array}$ & Top soil & $8-90$ & NA & $350-2500 \mathrm{~nm}$ & 0.76 & 4.9 & $\begin{array}{l}\text { (Shepherd } \\
\text { and Walsh, } \\
\text { 2002) }\end{array}$ \\
\hline $\begin{array}{l}\text { NSW } \\
\text { Australia }\end{array}$ & $\begin{array}{l}\text { Top and sub } \\
\text { soil }\end{array}$ & $8-98$ & 23 & $250-2500 \mathrm{~nm}$ & 0.53 & 14.5 & $\begin{array}{l}\text { (Islam et al., } \\
\text { 2003) }\end{array}$ \\
\hline $\begin{array}{l}\text { NSW } \\
\text { Australia; } 17 \\
\text { ha field }\end{array}$ & Top soil & $58-84$ & 5 & $1000-2500 \mathrm{~nm}$ & 0.59 & 3.3 & $\begin{array}{l}\text { (Viscarra } \\
\text { Rossel et al., } \\
2006 b)\end{array}$ \\
\hline $\begin{array}{l}\text { Canadian } \\
\text { district }\end{array}$ & Profiles & $1-98$ & NA & $1100-2498 \mathrm{~nm}$ & 0.65 & 17.6 & $\begin{array}{l}\text { (Malley et } \\
\text { al., 2000) }\end{array}$ \\
\hline
\end{tabular}

Not available

\subsection{Plant nutrients}

Due to their often direct relationship to plant nutrition, plant nutrients such as $\mathrm{N}, \mathrm{P}, \mathrm{K}, \mathrm{Fe}, \mathrm{Ca}, \mathrm{Na}, \mathrm{Mg}$, and methods for their measurement attract much interest in agriculture. In PA practices such as variable rate fertilization, data on plant-available $\mathrm{P}$ and $\mathrm{K}$, which are fairly stable parameters over time, are important for high resolution soil mapping. Nitrogen is by far the most important nutrient in most agricultural systems. Plant $\mathrm{N}$ uptake occurs mainly in the form of nitrate or ammonium, but as these sources are very dynamic, estimates of their concentrations are very variable. Plant nutrients are not expected to have direct spectral absorption features in the vis-NIR region. Correlations found to vis-NIR spectra are often weak, but there are exceptions, for example, Chang et al. (2001), Ehsani et al. (1999), Groenigen et al. (2003), Krischenko et al. (1992), Moron and Cozzolino (2003), Mouazen et al. (2006a; 2007), Pereira et al. (2004), Shibusawa et al. (2001), Udelhoven et al. (2003). These authors report highly variable coefficients of determination $\left(\mathrm{R}^{2}\right.$; in parentheses) for mineral $\mathrm{N}(0.20-0.99)$, available $\mathrm{K}(0.56-$ $0.83)$, exchangeable $\mathrm{K}(0.11-0.55)$, Ca (0.75-0.89), Fe (0.64-0.91), Na (0.09-0.44), Mg (0.53-0.82), and $\mathrm{P}(0.23-0.92)$. The occasionally successful calibrations may be attributed to locally present co-variation to spectrally active constituents. Such co-variations may of course vary between data sets. The wealth of reference methods available for the assessment of these parameters may add to the large variation in the results. However, by enriching a Yolo loam soil with ammonium sulphate, ammonium nitrate and calcium nitrate, Upadhyaya et al. (1994) obtained high coefficients of correlations for prediction of nitrate, but the RMSE values of 6-44 would still corresponded to approximately $15-100 \mathrm{~kg} \mathrm{~N} \mathrm{ha}^{-1}$.

The potential for vis-NIR to predict extractable $\mathrm{P}$ in soil has been relatively well studied as $\mathrm{P}$ is the second most important plant nutrient after $\mathrm{N}$ and is as well a limited natural resource. Results reported for $\mathrm{P}$ are, as indicated above, among the most variable. Some authors report successful calibrations and others absolute failure. Udelhoven et al. (2003) failed to predict CAL-extractable P (Schuller, 1969) at the regional scale, but at the field scale it was fairly well predicted. This was attributed to secondary 
correlations to other variables not measured in the study. In agricultural fields this is reasonable as $\mathrm{P}$ (and other nutrients) is removed with the yield and will relate to the size of the yield. Depending on the extent to which clay and organic matter regulate the harvest the depletion of plant available $\mathrm{P}$ will relate to clay and SOM and by co-variation also to vis-NIR, if P has been applied homogenously. This type of variation can, however, not be expected to be valid across fields or farms.

To some extent the variable performance of calibrations could also be attributed to the type of $\mathrm{P}$ measured with the reference method (extractable, available) and the corresponding laboratory method used. The large variety of methods employed to estimate available $\mathrm{P}$ are not always very well correlated (Mamo et al., 1996; Zbiral and Nemec, 2002). Chang et al. (2001) found that Mehlich III (Mehlich, 1984) extractable cations in general were better predicted than those extracted by NH4OAc. Bogrekci and Lee (2005) and Maleki et al. (2006) suggested that P correlates to the vis-NIR through different soil components that bind to phosphorus. If this is the case, it can also be assumed that there are differences in the correlations between different extraction methods for P and such P-soil complexes. The mechanism for calibration of available $\mathrm{P}$, co-variations or spectral features, is a subject that requires further investigation.

\section{5. $\mathrm{pH}$ and lime requirement}

Soil $\mathrm{pH}$ is an important fertility regulator. As nutrient solubility is generally $\mathrm{pH}$-dependent, plant root development can be restricted by unfavorable $\mathrm{pH}$-values. Biological activity, decomposition, mineralization, etc., in soil are also strongly influenced by the $\mathrm{pH}$. Generally, a $\mathrm{pH}$ close to 6.5 is regarded as ideal and liming is often undertaken to regulate low $\mathrm{pH}$. Soil $\mathrm{pH}$, or proton activity, is not expected to have a direct spectral response, but has still been more or less well predicted in several cases. Chang et al. (2001) suggested that this was due to co-variation to spectrally active soil constituents such as organic matter and clay. $\mathrm{R}^{2}$ values at the country or state scale ranging between 0.55 and 0.77 indicate the existence of fairly general correlations to vis-NIR spectra (Chang et al., 2001; Islam et al., 2003; Mouazen et al., 2006a; Pirie et al., 2005; Shepherd and Walsh, 2002), but it must also be recognized that the calibrations rarely perform better than an RMSE of one-third or half a $\mathrm{pH}$ unit. This may be high for estimations of within-field variations of lime requirement, as it corresponds to up to 10-15 tons of lime per ha in a clayey soil. However, field- or farm-specific calibrations have been shown to perform better, with RMSE values between 0.17 and 0.31 and R2 values between 0.54 and 0.92 (McCarty and Reeves, 2006; Reeves et al., 1999; Shibusawa et al., 2001; Viscarra Rossel et al., 2006c). Reeves et al. (1999) found that moving vis-NIR calibrations from one agricultural site to another caused a much greater loss in precision for $\mathrm{pH}$ and some other indirectly predicted parameters than it did for organic $\mathrm{C}$ and $\mathrm{N}$. This indicates that the co-variations upon which indirect calibrations are built may be very different at different locations. For example, correlation spectra to $\mathrm{pH}$ have been reported to be very similar to those to clay and CEC (Islam et al., 2003; Pirie et al., 2005), while others did not find any co-variation to clay or any other measured soil parameter (Chang et al., 2001). Despite this, R2 exceeded 0.55 in all three cases.

The $\mathrm{pH}$ of a soil is regulated by a variety of factors. The CEC is important for the buffering capacity of soil and is in turn related to the clay fraction and organic matter content. Soil mineralogy as such is important as minerals are characterized by different acidity, an effect which is exaggerated by weathering. Carbonates are present to varying degrees in many soils. As mentioned (Sections 2.1 and 2.2), all of these factors are spectrally active, which could result in rather complex calibration mechanisms for $\mathrm{pH}$. It is also easy to accept that the mechanisms can vary from one data set to another. In addition, the practice of

liming to increase the $\mathrm{pH}$ of acidic soils and thereby improve fertility can be expected to alter, or at least disrupt, the mentioned relationships. The somewhat contradictory results and the difficulties in transferring calibrations geographically, as exemplified above, are therefore in line with expectations.

\subsection{Organic matter quality and microbial processes}

The importance of soil biological processes for agriculture and forestry, as well as for environmental management, is unquestionable. As discussed earlier, organic matter absorbs in the vis-NIR region and 
prediction of SOM and SOC has attracted much attention. Even more interesting with regard to biological processes is the potential ability to correlate vis-NIR to the quality of the organic matter. In addition to direct estimations of organic fractions, microbial parameters including biomass, several respiration measurements and the potential to mineralize $\mathrm{C}$ and $\mathrm{N}$, are frequently used indicators for SOM quality. A number of studies, predominantly on forest soils from the $\mathrm{O}$ and $\mathrm{A}$ horizons, have related vis-NIR to microbial biomass $\mathrm{C}$ and $\mathrm{N}$ and reported $\mathrm{R}^{2}$ values in the range 0.6 to over 0.9 (Cécillon et al., 2008; Chodak et al., 2002, 2007; Couteaux et al., 2003; Ludwig et al., 2002; Meder et al., 2007; Pietkäinen and Fritze, 1995; Rinnan and Rinnan, 2007). Some studies have also been made on arable soils, but with less accurate results (Chang et al., 2001; Reeves et al., 1999, 2006). Couteaux et al. (2003) presented the highest $\mathrm{R}^{2}$ values of 0.96 and 0.97 for biomass $\mathrm{C}$ and $\mathrm{N}$, respectively. However, these high values appear somewhat overoptimistic, as a large group of well-predicted subsoils with extremely low values and very low residuals compared with the rest of the data set presumably influenced the correlation coefficients. There was also a tendency for separation between samples from different locations, with sometimes questionable correlations within each location. Rinnan and Rinnan (2007) failed to predict microbial N but found vis-NIR to be a useful tool to predict fungal biomass by predicting ergosterol content. This was supported by Pietkäinen and Fritze (1995). Comparable results to those for microbial biomass have also been obtained in predicting total or basal respiration (Chang et al., 2001; Chodak et al., 2002, 2007; Fystro, 2002; Ludwig et al., 2002; Palmborg and Nordgren, 1993; Pietkäinen and Fritze, 1995).

While $\mathrm{C}$ processes have attracted more attention among forest soil researchers, attempts to predict nitrogen mineralization have mainly been made on arable soils. Several studies on vis-NIR predictions for mineralisable $\mathrm{N}$ measured as accumulated mineral $\mathrm{N}$ after aerobic or anaerobic incubations have reported promising results, with $\mathrm{R}^{2}$ values between 0.7 and 0.8 and RPD values of about 2 (Chang et al., 2001; Fystro, 2002; Ludwig et al., 2002; Russell, 2003). Others have obtained less accurate results $\left(\mathrm{R}^{2}<0.5\right)$ (Reeves et al., 1999; Shepherd and Walsh, 2002; Terhoeven-Urselmans et al., 2006; van Groenigen et al., 2003). Chang et al. (2005) presented intermediate results for 400 cross-validated samples $\left(\mathrm{R}^{2}=0.6\right.$, RPD $=1.6$ ), with less accurate results when a small subset of the samples from a different location was used for validation. The same problem was found when predicting biomass $\mathrm{C}$ and $\mathrm{N}$ in soils in two long term field experiments in Maryland, USA (Reeves et al., 1999) when predicting one experiment with a calibration on the other. Terhoeven-Urselmans et al. (2006) emphasized the need for large sample sets with sufficient diversity when predicting biological characteristics.

For soils with low $\mathrm{C}$ content (i.e., most arable soils compared with the organic layers in forest soils), the co-variation between the predicted biological parameters and total or organic amount of $\mathrm{C}$ and $\mathrm{N}$ is likely to form the basis for the explained variation in vis-NIR calibrations (Chang et al., 2001; Fystro, 2002; Reeves et al., 1999, 2006; Russell, 2003). Nevertheless, the inability of total or organic C and N to explain all the variation that is explained by vis-NIR predictions of different soil biological characteristics (Fystro, 2002; Reeves et al., 1999; Reeves et al., 2006) suggests that vis-NIR can be used for predictions of SOM quality as well as quantity.

For practical applications, the possibility to estimate actual rather than potential $\mathrm{N}$ mineralization would of course be advantageous. However, this is very difficult due to unpredictable factors influencing mineralization such as weather and temperature conditions. Nitrogen uptake by a crop is an indirect measurement of the soil $\mathrm{N}$ made available through mineralization, and can be interpreted relatively directly for practical management. Vis-NIR spectroscopy has been used to predict $\mathrm{N}$ uptake in greenhouse pot experiments with promising results, cross-validated $\mathrm{R}^{2}$ of about 0.8 (Russell et al., 2002; Wagner et al., 2001). In the field, comparable results $\left(\mathrm{R}^{2}=0.7-0.8\right.$ and $\left.\mathrm{RMSE}=6-21 \mathrm{~kg} \mathrm{~N} \mathrm{ha}^{-1}\right)$ have been found for $\mathrm{N}$ uptake in cereal and rice crops within single or nearby fields (Börjesson et al., 1999; Dunn et al., 2000; Stenberg et al., 2005; Wetterlind et al., 2008a), thus indicating the feasibility of calibrations over smaller areas with similar soil and weather conditions. However, one out of two rice experiments in south-eastern Australia only resulted in $\mathrm{R}^{2}$ of 0.5 (Dunn et al., 2000). Van Groenigen et al. (2003) reported poor 
prediction results of $\mathrm{N}$ uptake in a Californian rice field $\left(\mathrm{R}^{2}=0.19, \mathrm{RPD}=1.1\right)$. Notably, the range in $\mathrm{N}$ uptake in the Californian field was considerably smaller than that reported in other studies. In addition, the range of total soil C (9-16 $\left.\mathrm{g} \mathrm{kg}^{-1}\right)$ was generally small compared to those reported by Börjesson et al. (1999), Stenberg et al. (2005) and Wetterlind et al. (2008a). Wetterlind et al. (2008a) failed to predict N uptake of winter wheat at one field with large variations in $\mathrm{N}$ uptake but only small variations in SOM content (corresponding to $12-32 \mathrm{~g} \mathrm{~kg}^{-1} \mathrm{C}$ in the top $30 \mathrm{~cm}$ ) suggesting that vis-NIR predictions of $\mathrm{N}$ uptake could be limited to fields with quite large variations in SOM content. Similarly to the studies on other biological characteristics, vis-NIR predictions could explain more of the variation in $\mathrm{N}$ uptake compared with organic C (Börjesson et al., 1999; Stenberg et al., 2005). Results from the study by Wetterlind et al. (2008a) indicated that the additional predictive capacity of vis-NIR was related to soil texture.

Stenberg et al. (2005) predicted $\mathrm{N}$ uptake in one field with a calibration model created from a nearby field with $\mathrm{R}^{2}$ of 0.6 and RPD 2.5, but building reliable prediction models for $\mathrm{N}$ uptake over larger areas has so far proven to be more difficult (Fox et al., 1993; Russell et al., 2002; Wetterlind et al., 2008a). However, 50 out of the 95 sites studied by Fox et al. (1993) had received farmyard manure and 25 had a legume crop in the previous year. Such short-term boosting of $\mathrm{N}$ mineralization was suggested to mask the variation in soil mineralization from SOM and thus result in poor predictions (Wetterlind et al., 2008a).

\subsection{Heavy metals and other soil contaminants}

Pure metals do not absorb in the vis-NIR region. However, they can be detected because of co-variation with spectrally active components. For example, they can be complexed with organic matter, associated with hydroxides, sulfides, carbonates, or oxides that are detectable in the vis-NIR, or adsorbed to clay minerals. Malley and Williams (1997) first attempted predictions of heavy metals in freshwater sediments using vis-NIR (1100-2500 nm). They reported R2 values between vis-NIR-predicted and chemicallyanalyzed metal concentrations of 0.63 for $\mathrm{Cd}$; 0.91 for $\mathrm{Cu} ; 0.93$ for $\mathrm{Zn} ; 0.81$ for $\mathrm{Pb} ; 0.88$ for $\mathrm{Ni}$; 0.93 for $\mathrm{Mn}$; and 0.86 for $\mathrm{Fe}$. The authors attributed most of the variance in heavy metal concentrations to organic matter content. Kooistra et al. (2001) researched the use of vis-NIR spectroscopy for the assessment of soil $\mathrm{Cd}$ and $\mathrm{Zn}$ contamination in river floodplains and reported good predictions, with $\mathrm{R} 2$ of 0.94 for $\mathrm{Cd}$ and 0.95 for $\mathrm{Zn}$. They attributed these good results to the associations of the metals with SOM and clay content, which are spectrally active in vis-NIR. Kemper and Sommer (2002) used vis-NIR (350-2400 $\mathrm{nm}$ ) for predictions of $\mathrm{As}, \mathrm{Cd}, \mathrm{Cu}, \mathrm{Fe}, \mathrm{Hg}, \mathrm{Pb}, \mathrm{S}, \mathrm{Sb}$, and $\mathrm{Zn}$ in soils polluted by a mining accident and reported R2 values between predicted and chemically analyzed concentrations of 0.84 for As; 0.72 for Fe; 0.96 for $\mathrm{Hg}$; 0.95 for $\mathrm{Pb} ; 0.87$ for $\mathrm{S}$; and 0.93 for $\mathrm{Sb}$. Analysis of these calibrations showed that most wavelengths important for prediction could be attributed to absorption features of iron oxides, clay minerals and carbonate. These metals were also highly correlated to each other. Results for $\mathrm{Cd}, \mathrm{Cu}$, and $\mathrm{Zn}$ were less accurate, with R2 values of $0.51,0.43$, and 0.24 , respectively. These metals were less correlated to those that were more accurately modeled. Elements that are highly correlated to each other were better predicted. Siebielec et al. (2004) compared vis-NIR with mid-IR predictions of $\mathrm{Zn}, \mathrm{Pb}$, and $\mathrm{Cd}$ and showed that calibrations were significantly better using mid-IR spectra. Good predictions were attributed to soil texture and the presence of Fe-oxides. Wu et al. (2005a) examined the potential for visNIR to assess contamination by $\mathrm{Ni}, \mathrm{Cr}, \mathrm{Cu}, \mathrm{Hg}, \mathrm{Pb}, \mathrm{Zn}$ in suburban soils in China and found that predictions for $\mathrm{Pb}, \mathrm{Zn}$, and $\mathrm{As}$ were better than those for $\mathrm{Ni}, \mathrm{Cr}, \mathrm{Cu}$, and $\mathrm{Hg}$. They attributed this to the better correlation of $\mathrm{Pb}, \mathrm{Zn}$, and $\mathrm{As}$ to $\mathrm{Fe}$ and therefore concluded that element sorption by spectrally active Fe oxides was the major mechanism by which predictions using vis-NIR occurred. Wu et al. (2005b) investigated the use of vis-NIR for predictions of $\mathrm{Hg}$ in suburban agricultural soils in China and found that $\mathrm{Hg}$ was correlated with the absorption features of goethite and clay minerals. They suggested that this was the mechanism by which spectrally featureless $\mathrm{Hg}$ was predicted by vis-NIR spectra. Wu et al. (2007) produced some further data suggesting that the correlation between heavy metals and spectrally active soil components such as organic matter and clay but particularly $\mathrm{Fe}$ is the major predictive mechanism. Bray et al. (2009) used a vis-NIR and mid-IR diagnostic screening procedure for detection of 
contamination by heavy metals $(\mathrm{Cd}, \mathrm{Cu}, \mathrm{Pb}$, and $\mathrm{Zn})$ and polycyclic aromatic hydrocarbon (PAH) in urban soils. They used ordinal logistic regressions for predictions of either contaminated or uncontaminated soil at different thresholds and found that the mid-IR technique produced only slightly better prediction accuracies. This methodology appears to be particularly useful for the screening of soil contaminants.

\subsection{Soil moisture}

There are many reasons to measure soil moisture. Apart from the obvious point of water being a dominant regulator of plant growth and soil biology as a whole, more specifically it regulates important soil processes such as nitrification/denitrification and hydrological processes such as leaching and erosion. Moisture also influences the results of other measurements, for example penetration resistance, while in the laboratory, the analytical results of air- or oven-dried (typically up to $50^{\circ} \mathrm{C}$ ) soils have to be corrected for hygroscopic moisture. Various forms of water absorb strongly in the near infrared. This is due to overtones and fundamentals of the three fundamental vibration frequencies of $\mathrm{H} 2 \mathrm{O}$; symmetric and asymmetric $\mathrm{O}-\mathrm{H}$ stretching and $\mathrm{O}-\mathrm{H}$ bending (Hunt, 1977). Water incorporated into the lattice of some clay minerals absorbs strongly near 1400 and $1900 \mathrm{~nm}$ and is obviously directly related to the mineralogy of the sample (Fig. 5), as discussed in the mineralogy section (Section 2.2). Water adsorbed as a thin layer onto exposed surfaces and free liquid water filling pore spaces has the general effect of decreasing the albedo. This effect can be largely attributed to a change in real refractive index of the medium surrounding the soil particles from that of air to that of water, which is higher and closer to soil particles. The resulting lower contrast causes more forward scattering and the path length before reemerging is longer, increasing the chances of absorbance (Twomey et al., 1986; Whalley et al., 1991). As porosity and the refractive index of soil particles vary between soils, a general relationship between overall albedo and gravimetric or volumetric moisture cannot be found. Whalley et al. (1991) also found that shrinking of kaolinite clay soils upon drying slowed the increase in reflectance compared with sandy soils. Nevertheless, the feature of increased forward scattering is suggested to relate to the thickness of the water film and thus to moisture tension (Baumgardner et al., 1985). In fact, Lobell and Asner (2002) found that the degree of saturation could be fairly well modeled by a general exponential function between 1100 and $2500 \mathrm{~nm}$. It should be recognized that the change in albedo is largely corrected for by any of the transformations of spectra commonly applied to correct for scatter effects and baseline shift (Section 3.2). However, the reflectance curve shape also changes due to the strong absorption bands near 1400 and $1900 \mathrm{~nm}$ and the weaker bands near 970, 1200, and $1780 \mathrm{~nm}$ (Baumgardner et al., 1985). Bands near $1900 \mathrm{~nm}$ has been found to be better for quantitative estimation of soil moisture content than bands near $1400 \mathrm{~nm}$ (Bowers and Hanks, 1965; Dalal and Henry, 1986), probably because those near $1400 \mathrm{~nm}$ coincides with that of the hydroxyl ion (Clark et al., 1990). Due to the fact that the absorption bands of hydroxyl ions associated to clay minerals and water bound in the clay lattice vary with mineral types (Clark, 1999) and coincide with the water removed upon oven drying, the quantification of moisture across soil types is difficult (Ben-Dor et al., 1999).

Despite the potential problems in finding simple relationships between albedo change or reflectance at the specific water absorption bands discussed above, there have been some successful attempts involving multivariate calibration of spectral bands to water content. For example, Bullock et al. (2004) found bands near $1900 \mathrm{~nm}$ to be better than those near $1400 \mathrm{~nm}$, but they also showed that PLS regression of the 1100$2500 \mathrm{~nm}$ region was even better. With MLR calibrations predictions of hygroscopic moisture of air dry soils (0.2-11.6\% water) made on samples covering arid and semi-arid zones of Israeli soils were moderately successful $(\mathrm{R} 2=0.62, \mathrm{RMSE}=1.55 \%)$ (Ben-Dor and Banin, 1995a). Considerably better results were achieved by Dalal and Henry (1986) for eight profiles from each of three major soil series in Darling Down, Queensland, Australia. The R2 was 0.93 and the RMSE 0.58\% for samples ranging between 3.5\% and 13\% moisture. The two studies used different wavelengths; 2120 and $2362 \mathrm{~nm}$ for the Israeli soils and 1926, 1954, and $2150 \mathrm{~nm}$ for the Australian. One explanation to the discrepancy in 
calibration performance could be that the soil type potentially varied more within the Israeli soils, which spanned a larger geographical area. The potential influence of soil type was supported by the results of Chang et al. (2005) who produced a reliable PLS calibration for hygroscopic water from a location in Iowa, USA, ranging between $1.3 \%$ and $5.8 \%$ water content, which lost all predictive power when the calibration was moved to a Minnesota site. A way around the soil type problem might be a procedure suggested by Chang et al. (2001), who within a data set of 802 samples selected the 30 spectrally most similar for each sample to predict and made a unique calibration on these 30 . Unfortunately the procedure was not compared against one using separate calibration and validation sets, but the R2 was 0.84 and the RMSE $0.5 \%$.

Table 4. Validation results for soil moisture (\%) of field moist soil.

\begin{tabular}{|c|c|c|c|c|c|c|c|}
\hline Origin & $\begin{array}{l}\text { Spectra } \\
\text { acquisition }\end{array}$ & Range & S.D. & $\begin{array}{l}\text { Spectral } \\
\text { range }\end{array}$ & $\begin{array}{l}\text { Validation } \\
\mathbf{R}^{2}\end{array}$ & $\begin{array}{l}\text { Validation } \\
\text { RMSE }\end{array}$ & Reference \\
\hline $\begin{array}{l}\text { Four } \\
\text { profiles, } \\
\text { Israel }\end{array}$ & Field & $9-29$ & N.A. ${ }^{*}$ & $\begin{array}{l}350- \\
2500 \mathrm{~nm}\end{array}$ & 0.98 & 1.1 & $\begin{array}{l}\text { (Ben-Dor et al., } \\
\text { 2008) }\end{array}$ \\
\hline $\begin{array}{l}\text { Five Iowa } \\
\text { soil series }\end{array}$ & Lab & $6-23$ & 3.5 & $\begin{array}{l}400- \\
2498 \mathrm{~nm}\end{array}$ & 0.74 & 2.0 & $\begin{array}{l}\text { (Chang et al., } \\
\text { 2005) }\end{array}$ \\
\hline $\begin{array}{l}\text { Top soil } \\
\text { from Eight } \\
\text { Kansas } \\
\text { fields }\end{array}$ & Field & $7-31$ & 4.9 & $\begin{array}{l}920- \\
1718 \mathrm{~nm}\end{array}$ & $0.40-0.65$ & $3.6-2.8$ & (Christy, 2008) \\
\hline $\begin{array}{l}16 \text { Illinois } \\
\text { profiles }\end{array}$ & $\begin{array}{l}\text { Lab: } \\
\text { Remoistened } \\
\text { undisturbed } \\
\text { soil } \\
\text { cores }\end{array}$ & $1-70$ & N.A. & $\begin{array}{l}1603- \\
2598 \mathrm{~nm}\end{array}$ & 0.88 & 6.4 & $\begin{array}{l}\text { (Hummel et al., } \\
\text { 2001) }\end{array}$ \\
\hline $\begin{array}{l}\text { Top soil } \\
\text { from } 7 \text { ha } \\
\text { field, } \\
\text { Belgium }\end{array}$ & $\begin{array}{l}\text { Calibration in } \\
\text { lab: } \\
\text { Remoistened; } \\
\text { Validation in } \\
\text { lab and field }\end{array}$ & $0.5-26$ & 8.4 & $\begin{array}{l}300- \\
1700 \mathrm{~nm}\end{array}$ & $\begin{array}{l}\text { Lab: } 0.98 \\
\text { Field: } 0.75\end{array}$ & $\begin{array}{l}\text { Lab: } 1.6 \\
\text { Field: } 2.5\end{array}$ & $\begin{array}{l}\text { (Mouazen et al., } \\
\text { 2005a) }\end{array}$ \\
\hline $\begin{array}{l}\text { Seven } \\
\text { California } \\
\text { soils }\end{array}$ & $\begin{array}{l}\text { Lab: } \\
\text { Calibration } \\
\text { remoistened } \\
\text { and finely } \\
\text { ground; } \\
\text { Validation } \\
\text { field moist } \\
\text { coarse }\end{array}$ & $\sim 5-22$ & N.A. & $\begin{array}{l}1400- \\
2400 \mathrm{~nm}\end{array}$ & 0.96 & 1.0 & $\begin{array}{l}\text { (Slaughter et al., } \\
\text { 2001) }\end{array}$ \\
\hline $\begin{array}{l}30 \text { Illinois } \\
\text { soils }\end{array}$ & $\begin{array}{l}\text { Lab: } \\
\text { Remoistened }\end{array}$ & $1-40$ & N.A. & $\begin{array}{l}1630- \\
2650 \\
\mathrm{~nm}\end{array}$ & 0.94 & 1.9 & $\begin{array}{l}\text { (Sudduth and } \\
\text { Hummel, 1993) }\end{array}$ \\
\hline
\end{tabular}

\footnotetext{
${ }^{*}$ Not available
} 
For field-moist soils the aim of most studies are measurements in the field, but calibrations are nevertheless often performed on laboratory spectra (Table 4). Despite the strong absorption of water in the vis-NIR RMSE values for prediction of water are surprisingly high. Compared for example with carbon or clay calibrations (Tables 2, 3, and 4) water is at least as well predicted, but not considerably better as might be expected. As several studies on water are based on field measurement (Table 4) this could be one explanation to why they are not, but there are no strong indications that validations in the field perform worse than in the laboratory (Table 4). Actually the two best results were accomplished through validation in the field (Table 4; Ben-Dor et al., 2008; Slaughter et al., 2001). Nevertheless, results by Mouazen et al. (2005a) indicate that some of the explanation for moisture calibrations not performing better than they do may be due to problems introduced by on-the-go measurements (Section 4). Hummel et al. (2001) experienced a tendency for under-estimating the wettest soil cores analyzed, which the authors attributed to the possible presence of a layer of water on some of the saturated samples, potentially causing specular reflectance. The upper surface (on which measurements were made) of a saturated soil core would also be slightly less moist than the average of the core due to gravity. Also for water the influence of scale could be an issue. Mouazen et al. (2006b) reported higher accuracy of prediction $(\mathrm{R} 2=0.98$; RMSEP $=1.6 \%)$ of soil moisture content of a calibration developed for one field of about 7 ha compared with a calibration developed on several fields distributed in Belgium and Northern France (R2 = 0.88; RMSEP $=2.5 \%$ ). This was attributed to variable color, texture, and origin.

\section{Factors influencing the performance and generality of vis-NIR calibrations}

\subsection{Sample pretreatment}

The dominant pretreatment of soils before vis-NIR analysis in the laboratory is drying and sieving, as for most other soil analytical methods. The standard procedure for chemical and physical analyses is air drying and passing crushed soil through a $2 \mathrm{~mm}$ sieve, and this procedure is commonly used for vis-NIR studies as well (Table 1). The crushing and sieving of soil removes stones $(>2 \mathrm{~mm})$ and course plant residues. It is also a basis for representative sub-sampling. Further grinding and sieving through finer mesh sizes can occur. The motive for such further grinding is to ensure a constant particle size effect on spectra (Ben-Dor and Banin, 1995b; Dunn et al., 2002).
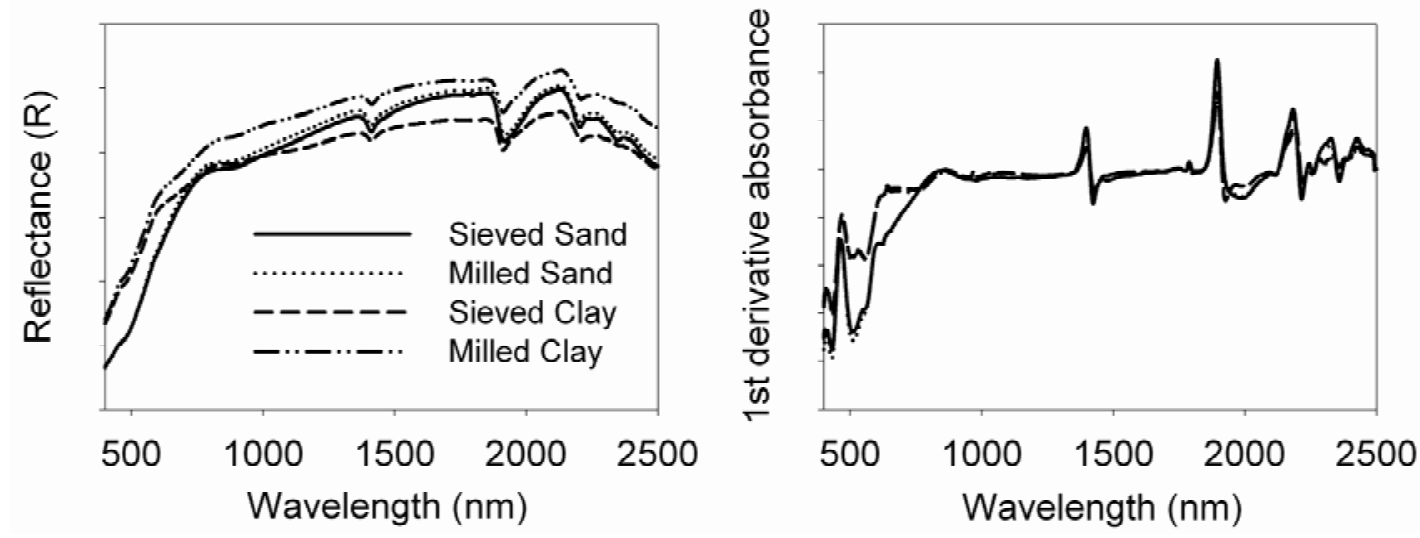

Figure 7. The effect of sieving $(<2 \mathrm{~mm})$ and milling on an un-aggregated sandy soil and a heavy, aggregated clay soil before and after transformation of reflectance spectra to first derivative absorbance spectra. 
There is no doubt that grinding of soil particles has a substantial effect on spectra, as the overall reflectance increases. The effect is especially large for soils high in clay as aggregates are crushed. However, these effects can be minimized through baseline or scatter correction transformation (Fig. 7; Section 4). There are few published studies actually testing the effect on prediction performance of different milling procedures. Fystro (2002) found a slightly increased prediction error for organic carbon and total nitrogen using air-dry, ball-milled $(<0.5 \mathrm{~mm})$ soil compared with coarse $(<4 \mathrm{~mm})$ soil, as did Russell (2003) for soil treated in a puck and ring grinder compared with soil crushed and sieved through 2 $\mathrm{mm}$. Barthes et al. (2006), on the other hand, reported a positive result of grinding $(<0.2 \mathrm{~mm})$ compared with sieving soil $(<2 \mathrm{~mm})$. They suggested that the contradictory results were due to different responses to grinding between aggregated clay soils and single-grain, coarse-textured soils, as crushing clay aggregates would produce more homogeneous samples. For clay content it has been reported that ball milling has a detrimental effect on prediction performance (Stenberg et al., 2000), supposedly due to alteration of the texture. Although these contradictions to the expected might be explained by the ferocity of the ball mill, Waiser et al. (2007) achieved better predictions of clay content from sliced, air-dried in situ soil cores than from milled soil $(<2 \mathrm{~mm})$. They attributed this to either random error or to the density of the sliced core being higher, resulting in a stronger reflectance signal. Drying of samples has a similar effect to grinding in that the total reflectance increases (Section 2.8), but in addition, absorption at the water absorption bands near 1400 and $1900 \mathrm{~nm}$ is reduced (Krishnan et al., 1980). The influence of moisture on prediction performance is discussed in Section 4.

\subsection{Data pre-treatment}

Spectral preprocessing with mathematical functions is commonly used to correct for non linearities, measurement, and sample variations and noisy spectra. In addition to chemical composition, spectra are also highly influenced by structural properties of the sample, which causes non linear light scattering effects, hence the epithet diffuse reflectance spectroscopy (Fig. 8). The main implication of this phenomenon is that energy not reflected by the sample is not directly related to absorbance. Most commonly, to attempt linearisation between absorbance and concentration, the measured reflectance (R) spectra (Fig. 9A) is transformed to $\log 1 / \mathrm{R}$ (Fig. 9B). Other transformations include the Kubelka-Munk and the Dahm equation (Dahm and Dahm, 2007). Dahm and Dahm (2007) provide an excellent account of the theory of diffuse reflection in scattering and non scattering samples.

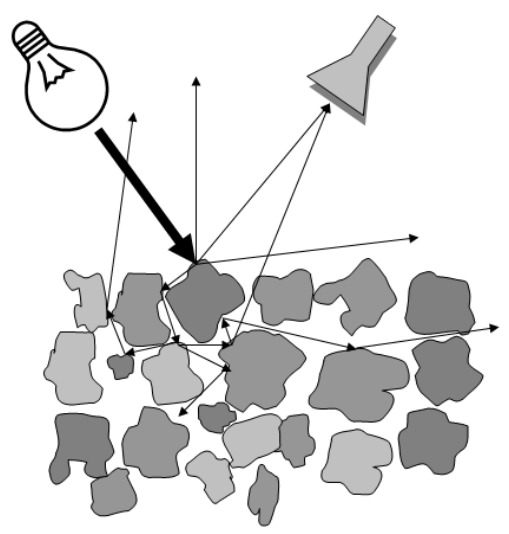

Figure 8. Illustration of diffuse reflectance. Incoming light from the left is scattered. Only a fraction of the reflected light reaches the receiving probe on the right and the rest is absorbed or lost. 

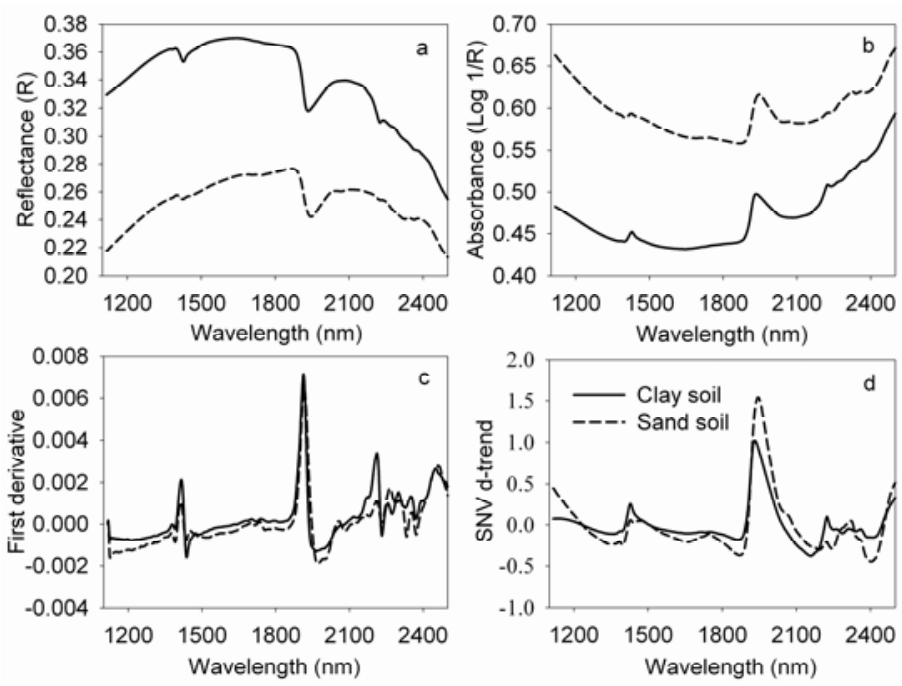

Figure 9. The effect of spectral transformations and preprocessing on (A) reflectance (R) spectra. The log $1 / \mathrm{R}$ transformation is shown in (B), preprocessing of the log $1 / \mathrm{R}$ spectra using the first derivative is shown in $(\mathrm{C})$, and the SNV with detrending in (D).

The particle size distribution of the sample affects the degree of scattering. A coarser structure increases the scatter (reduces reflection) and the apparent absorbance increases as path length increases. To enhance the more chemically relevant peaks in the spectra and reduce effects such as baseline shifts and overall curvature, various additional preprocessing transformations may be employed. For example, some of the more commonly used techniques include multiplicative scatter correction (MSC) (Geladi et al., 1985); first and second derivatives (Fig. 9C), simple additive baseline correction, the standard normal variate transform (SNV; Fig. 9D) with or without detrending (Barnes et al., 1989) and orthogonal signal correction (OSC) (Wold et al., 1998). Most spectroscopy-dedicated software contains a collection to choose from (e.g., Viscarra Rossel, 2008). Commonly used smoothing methods to reduce noise in spectral signals include averaging spectra, moving average and median filters and the Savitzky-Golay transform (Savitzky and Golay, 1964). Derivatives tend to amplify noise and therefore a smoothing algorithm is often used together with the derivatives. More recently, wavelets have been used to smooth and compress soil spectra, resulting in simpler and more robust calibrations (e.g., Viscarra Rossel and Lark, 2009).

For soil analysis there is no one single or combination of preprocessing techniques that will work with all data sets. For soil samples, the type and amount of preprocessing required are data-specific. Nevertheless, the first and second derivatives calculated by difference are by far the most popular. Derivatives perform baseline correction and enhance weak signals (Fig. 9C). The standard normal variate (SNV) combined with d-trending has a similar effect, but the enhancement of weak signals is not as pronounced (Fig. 9D).

\section{Field analyses}

Compared with diffuse reflectance analysis in the laboratory, in situ measurements with mobile or non mobile instrumentations use the full potential of the vis-NIR technology. This aspect is particularly useful for applications requiring soil data with high spatial resolution, for example, PA. In addition to the need for successful mechanical design and related technical systems for the collection of high resolution, high quality, spectra the influence of environmental factors such as ambient light, soil moisture content, structure, temperature, dust, contamination by stones and excessive residues, and the required actions to meet them have to be addressed when developing on-the-go measurement systems. Although Shonk et al. (1991) described an on-the-go spectroscopic soil sensor and Sudduth and Hummel (1993a) described a 
prototype for a portable field vis-NIR sensor over 15 years ago, it was not until recently that results from on-the-go measurements of soil properties were published (Christy, 2008; Mouazen et al., 2005a; Shibusawa et al., 2001).

Assuming that the instrumentation is robust enough for field operation, the construction has to allow a reflectance probe to sample good reproducible spectra. Instability due to dust and dirt on the probe and variable distances between the sensor and soil has been experienced (Shibusawa et al., 2000; Shonk et al., 1991; Stenberg et al., 2007). Sudduth and Hummel (1993b) tested the influence of potential sources of error in a field situation in laboratory experiments. They did not find sample preparation or presentation, or variable probe to sample distance to be the major sources of prediction error if a baseline correction was performed. They found that the sample moving relative the probe during scanning was introducing the largest error.

Recent systems developed for field measurements with modern scanning instruments apparently do not suffer significantly from moving samples. These systems include soil penetrating shanks equipped with a fiber optic probe (Fig. 10) protected by a sapphire glass at the bottom (Christy, 2008; Shibusawa et al., 2001; Stenberg et al., 2007), or without (Mouazen et al., 2005a). The bottom of the probe should be in close contact to the soil at all times. Automatic systems for identifying and filtering noisy and contaminated spectra are nevertheless required. Occasionally, lost probe-soil contact due to vibration and shakiness of the draught vehicle has been shown to result in noisy spectra (Stenberg et al., 2007). In addition, topographical variation and slope changes across the field are contributing factors. Mouazen et al. (2009) proposed a methodology to optimize the length of the tractor three-point link aiming at minimizing soil-to-probe distance variations, reporting improved prediction of extractable $\mathrm{P}$.

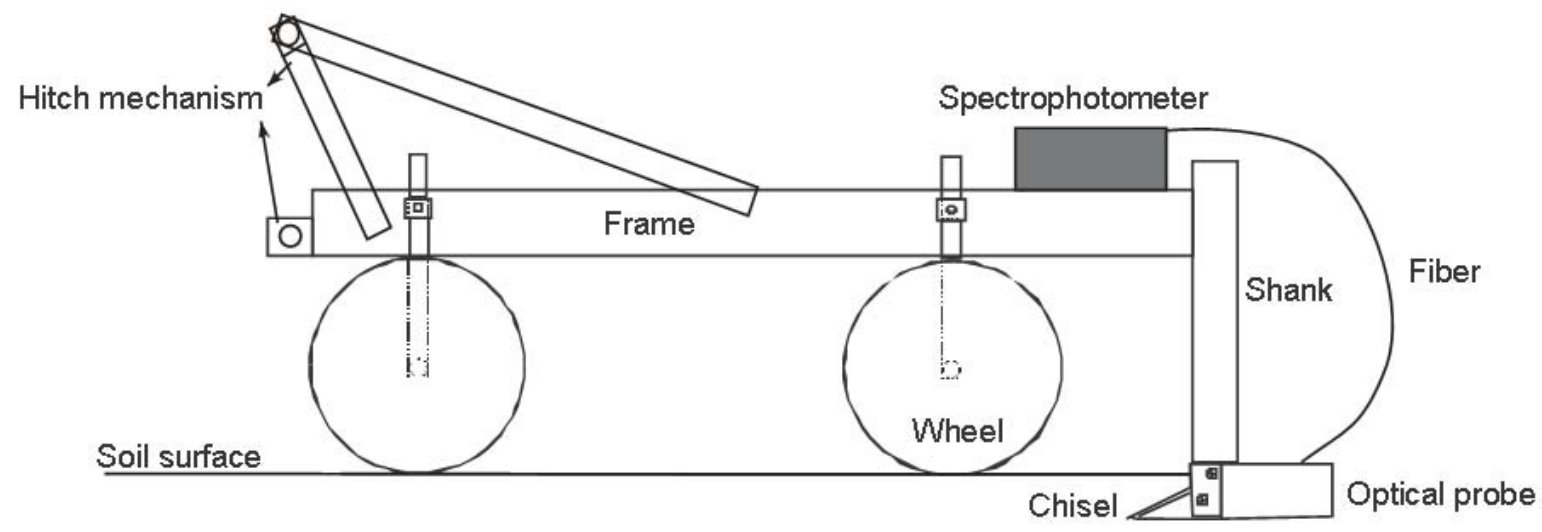

Figure 10. A soil penetrating shanks equipped with a fiber optic probe at the bottom.

Recently, the potential of field, point to point, vis-NIR spectroscopy to monitor soil properties has attracted interest for applications involving three-dimensional soil variation. Ben-Dor et al (2008) developed a so-called penetrating optical sensor to measure soil properties down the soil profile to provide data that can be used for soil type classification. Kusumo et al. (2010) reported good calibration quality for $\mathrm{C}$ and N (RPD 1/4 2.90-5.80) from spectral measurements taken from the vertical side of a vertically extracted soil core sampled at six depths from 15 to $315 \mathrm{~mm}$. However, spectra sampled from the horizontal cross-sections of $5 \mathrm{~cm}$ slices gave slightly less accurate predictions. This difference was attributed to a larger influence of roots in the upper soil layers on the horizontal cross-section. In addition the vertical sampling involved turning the soil core, resulting in a larger field of view. Viscarra Rossel et 
al. (2009) reported good estimates of soil color, mineral composition and clay content from in situ, field vis-NIR measurements of 10 different, open soil profiles in Australia.

There is much focus on the influence of moisture content on soil spectra, an obvious factor to consider in situ. The most apparent effect of moisture is the overall decrease in reflectance (Baumgardner et al., 1985; Bowers and Hanks, 1965). In vis-NIR this darkening is attributed to increased scatter due to an increase in the refractive index from air to water as surfaces are covered with adsorbed water (Section 2.8). In the NIR region $(>1000 \mathrm{~nm})$ water also has strong absorption bands, which may interfere with the spectral features of other soil components. Lobell and Asner (2002) showed for example that the absorption band depth of the clay mineral-associated band at $2200 \mathrm{~nm}$ was substantially reduced when moisture increased. At a volumetric water content of $40 \%$ the band depth approached zero. Such effects can potentially have a negative effect on calibration performance. However, in a laboratory experiment Stenberg (2010) found that standardized rewetting of samples up to $30 \mathrm{vol}-\%$ improved predictions of SOC and clay substantially. Using wavelength specific t-tests, Viscarra Rossel et al. (2009) compared laboratory spectra of sieved, dried soil to spectra of field moist soil sampled directly from open profiles. They found that except in the water absorption regions around $1400 \mathrm{~nm}$ and $1900 \mathrm{~nm}$ and in regions that are not primarily used to characterize soil mineral composition, field-collected spectra were not significantly different to spectra collected in the laboratory.

Waiser et al. (2007) evaluated the feasibility of vis-NIR spectroscopy for in situ quantification of clay content from a variety of parent materials. A slightly larger RMSE of $61 \mathrm{~g} \mathrm{~kg} 11$ was obtained for the field-moist in situ cores than for the air-dried (41 g kg_1). Mouazen et al. (2006a) reported the prediction accuracy of $\mathrm{pH}, \mathrm{C}, \mathrm{N}, \mathrm{P}, \mathrm{CEC}, \mathrm{Ca}, \mathrm{Mg}, \mathrm{Na}$, and $\mathrm{K}$ to be slightly improved when soil was dried. Conversely, Viscarra Rossel et al. (2009) found slightly better predictions of clay content for a range of Australian soils using field-collected spectra (RMSE 1/4 $79 \mathrm{~g} \mathrm{~kg}$ 1) compared to laboratory collected spectra of dry soil (RMSE $1 / 483 \mathrm{~g} \mathrm{~kg}$ 1). By comparing calibrations with field-moist and air-dried soil, Chang et al. (2005) found small differences, and in both directions, for total, inorganic and organic C, total $\mathrm{N}, \mathrm{pH}, \mathrm{CEC}$, mineralisable $\mathrm{N}$ and texture parameters. They concluded that the necessity of analyzing field-moist soils is not a major impediment to the deployment of commercial vis-NIRS soil analysis technology'.

The surface properties of the measured soil have been reported to influence calibration performance. Compared with laboratory measurements of milled, field-moist samples, Udelhoven et al. (2003) failed to Make useful calibrations for field-measured vis-NIR spectra. The difference was attributed to structure problems and micro shadow effects during the in situ measurements of unprepared soil. Samples with high moisture content may also be subjected to surface smearing effects that could reduce the prediction accuracy, as reported by Waiser et al. (2007). Shibusawa et al. (2000) used a micro CCD camera to monitor the quality of the prepared soil surface by a soil cutting tool followed by a flattener. They found that the roughness of the soil surface affected the absorption spectra and suggested transformation by the first derivative to eliminate this effect. One reason to interpret the effect of surface roughness might be the high scattering of light on the rough surface. A better understanding of the influence of soil surface characteristics and water on vis-NIR spectra and possible solutions through transformations, filtering, and calibration strategies are needed. Engineering aspects of sensing systems and soil probes should be considered for in situ, mobile and non mobile measurement systems.

Spatial variability of texture and moisture within agricultural fields is also suggested to affect the prediction accuracy of other soil properties during on-the-go measurement. Therefore, Mouazen et al. (2005b; 2006b) proposed a concept to eliminate these effects by classifying soil spectra measured on-thego into a few moisture or texture groups by PCA and factorial discriminant analyses. 
The idea of extending the range of the PLSR calibrations by 'spiking' a spectral library made from laboratory measurements calibration with field spectra was suggested by Viscarra Rossel et al. (2009). In their study, they produced better PLSR calibrations by 'spiking' their library of laboratory spectra with 74 field spectra. They showed that this technique can be a more practical option to developing spectral libraries for predictions of soil properties using spectra collected in situ at field conditions.

Christy (2008) described a complete working system from field measurement to predictions using an onthe-go vis-NIR sensor for top soil measurements combined with a calibration sample selection strategy. Sampled vis-NIR-spectra were clustered into the same number of clusters as calibration samples to be obtained. From each cluster one sample was selected to be close to the cluster center both spectrally and geographically. By a one-field-out validation procedure Christy (2008) also found that predictions for the left out field were better the more fields that were included in the calibration which was interpreted as an indication that results will continue to improve as more fields are augmented to the calibration.

Maleki et al. (2008) designed and implemented a soil sensor-based variable rate fertilization system for on-the-go application of phosphate according to variations in soil P as measured by on-the-go vis-NIR spectroscopy. In field experiment plots higher maize yield and smaller variations in plant indicators were found by variable rate application compared with uniform rate application.

\section{Strategies for practical use of vis-NIR spectroscopy for soil analysis}

\subsection{Local influence of target area}

For vis-NIR spectroscopy to gain any degree of uptake, the prime benefits of vis-NIR in terms of its rapidity, simplicity, and low cost of analysis compared with traditional analytical methods have to be exploited. Basically this means that sampling, handling, and pretreatment of samples and calibration procedures including reference analyses should be kept to a minimum. As mentioned repeatedly above, the geographical scale or the overall variation for which calibrations are representative clearly influences their absolute precision (Sudduth and Hummel, 1996). An obvious implication of this is that a calibration of high generality at district, country or greater scale may lack precision when predicting the variation at a smaller scale (Brown, 2007). To overcome these and similar limitations, a number of strategies have been proposed. Spiking (the complementation and re-calibration of a calibration set with known samples representative for the studied area) of general, or global, calibrations has been suggested and have given positive results for moving a calibration from one geographical region to another at the country level (Shepherd and Walsh, 2002; Viscarra Rossel et al., 2008a) and field scale (Reeves et al., 1999) and improved the performance for a small catchment with a global calibration (Brown, 2007) as well three landscape sites (Sankey et al., 2008). In these examples, from eight to approximately 400 spiking samples were used to improve the results significantly.

Shepherd and Walsh (2002) suggested that a widely sampled spectral library of the target area should be built, including reference data and calibrations. When using the library for prediction of new samples, the library and calibrations should be spiked and for the future extended with spectral outliers. This improved predictions of effective CEC in eastern African samples (n 1/4 697) with a southern African calibration set $(\mathrm{n}=274)$ by adding 53 eastern African spectral outliers. The improvement was not achieved with 53 randomly selected eastern African samples. This approach involved not only adding the spectral outliers to the calibration set, but also removing them from the samples to be analyzed. The removal of the spectrally most extreme samples may explain a large part of the improvement. A similar strategy was tested by Brown (2007) for down-scaling a large global calibration to a small catchment in Uganda. The general calibration was built on a global sample set with mainly US samples with additions from Africa, Asia, America, and Europe and catchment samples were divided into upland and dambo validation sets. For 
both sets calibrations for clay were slowly and continuously improved by spiking with catchment samples at increments of 10 up to 40 samples, and then the maximum of about 400 . For organic carbon it was mainly the dambo soils that gained from spiking, with almost full effect already with 20 additional samples. For both clay and carbon, there was a tendency for fully spiked calibrations to perform slightly better than calibrations based on all catchment calibration samples only. The same global sample set was also separately spiked with local samples from three temperate landscape sites in Montana (Sankey et al., 2008). The spiked global data set was always best for SOC, but for two sites global calibration samples only performed almost as good and for one site the local samples only did. For clay spiked global performed best at one site, local only at another, and at the third site all three methods performed very poorly. A strategy relying on very few calibration samples from the current target area has been suggested (Wetterlind et al., 2008b, Wetterlind et al., 2010). Data from Swedish farms suggest that rationality can be gained with farm-scale calibrations built on 25 samples only, targeted from about 100 ha, with clay and organic matter being predicted with high precision (Fig. 11). Kriged maps from predicted data on approximately 1.5 samples per ha improved the accuracy and changed maps radically compared with those kriged from 0.5 samples per ha as conventionally sampled and analyzed with reference methods (Wetterlind et al., 2008b).

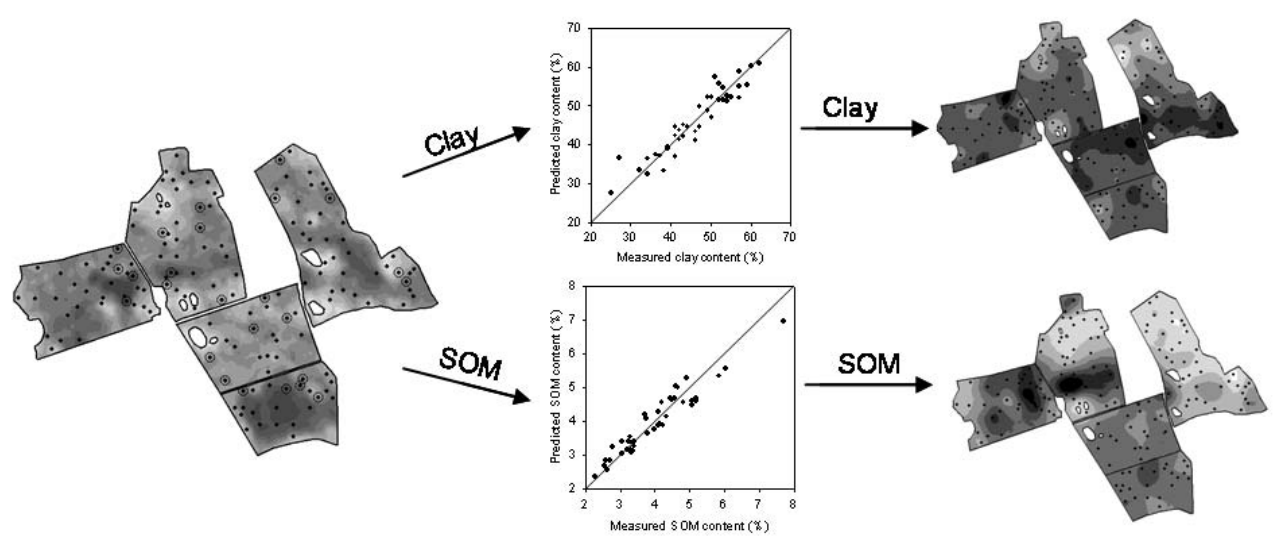

Figure 11. Electrical conductivity (ECa)mapping was used to target 1.5 sample points per ha (points in left map), 25 of these (circled) are used for vis-NIR calibrations for clay and SOM content. Independent validation of these calibrations in the middle. Calibrations are used to predict the resulting samples and the kriged maps are shown on the right. Adapted from Wetterlind et al. (2008b).

These are a few examples of calibration strategies at different scales focused on maintaining the benefits of vis-NIR spectroscopy by keeping calibration samples from the target area to a minimum still allowing local influences on calibrations. These examples all involved laboratory vis-NIR analyses, but similar approaches are of course relevant for field analyses. The generality of these results is impossible to judge due to the small amount of data, but this type of research is essential for the wider use of vis-NIR spectroscopy. Evaluated strategies and guidelines for sampling schemes and calibration techniques are required for practical use.

\subsection{Screening and mapping of overall soil variability}

The premise for this review is that vis-NIR spectra holds important information about soil. This relevance of vis-NIR spectra can be taken advantage of when sub-sampling a larger soil database to recover the larger part of the original variation within the sub-set. Basic methods for selecting samples out of principal component (PC) scores to recover the original variation with few samples have been tested for country and field scale (Stenberg and Nordkvist, 1996; Stenberg et al., 1995). The strategy improved the variation within sub-sets compared with random sampling for at least clay, total carbon and CEC at the country scale, and at the field scale also total N, pH, and available Mg. For a single field, Odlare et al. (2005) 
compared variograms and kriged maps from PC scores of vis-NIR spectra with those of conventionally analyzed total $\mathrm{C}$, clay, and $\mathrm{pH}$. Compared with the other parameters they found the variogram of PC 1 to be the most robust, but they did not claim a specific representativity to any of the soil parameters analyzed. Instead, they concluded that maps of PC 1 scores represented a combination of soil parameters and that the first PC could be used to capture the variation of the soil properties. At the landscape scale, Dematte et al. (2004) adopted a similar but more elaborate approach using a spectral reflectance-based strategy to assist soil surveys. Important wavelengths and their intensity were evaluated and clustered on a 350 ha area in Brazil. Organic matter, total iron, texture, and mineralogy were the soil attributes identified as most influential on reflectance features and intensity. Soil map demarcation lines and number of classes detected from soil spectra evaluation closely resembled those detected from conventional analytical soil survey methods. Viscarra Rossel and McBratney (2008) discuss the potential of soil spectroscopy and its application to digital soil mapping.

The detection and description of soil variation directly from vis-NIR spectra is an attractive strategy, as neither spectral nor reference libraries have to be created for calibration purposes. Nevertheless, when it comes to soil classification or surveys, spectral clusters have to be related to conventionally estimated soil units and reliability has to be validated. However, this may be accomplished with much less reference sampling than true calibration for specific soil parameters. For the rapid evaluation of soil variability, Islam et al. (2005) suggested calculating the area of a convex hull (Everitt, 2002) as defined by a twodimensional PCA score plot based on 250-2500 nm spectra. Although the convex hull area varied by a factor five, the correlations of area to $\mathrm{pH}$, organic carbon or clay content were very low.

\subsection{Soil quality and fertility assessment}

A number of studies have shown the potential for vis-NIR to be used directly for the characterisation of soil quality, or soil fertility. The rationale for this is, again, that the spectra contain information on soil organic and mineral composition - the fundamental building blocks of soil. Therefore the spectra themselves should be useful for characterizing changes in quality and or fertility. Shepherd and Walsh (2007) outlined a framework for "evidence-based diagnostic surveillance" to provide information on agricultural and environmental problems, identify cause and effect relationships in affected areas and to monitor the effect of interventions. Spectroscopy tools should be used in a screening step to differentiate predefined quantitative cases of affected or none affected. Vågen et al. (2006) tested the potential of visNIR soil spectral libraries for predicting and mapping soil properties in the highlands of Madagascar. The authors derived a spectral soil fertility index using ten commonly used agronomic indicators of soil fertility. They suggested that the method was able to separate the soils of the study area into ordinal soil condition classes. Awiti et al. (2008) evaluated the use of near infrared spectroscopy as a tool for diagnosing soil condition for agriculture and environmental management. They derived three soil conditions: good, average, and poor. The study indicated that vis-NIR spectroscopy was a good tool to indicate areas for different management.

Viscarra Rossel et al. (2010) developed a soil fertility index for sugar cane production and modeled it spatially using vis-NIR spectra and terrain attributes derived from a digital elevation model (DEM). The rational for their work was that: (i) the spectra account for the soil mineral and organic composition and (ii) the terrain data account for soil and landscape interactions that are important for crop growth. The authors presented a versatile methodology that can be used for rapid and accurate determination of soil fertility using only soil vis-NIR spectra and terrain attributes.

\section{General and future aspects}

There are several soil attributes that often are well estimated with vis-NIR spectroscopy. The most obvious ones are soil texture, especially clay content, mineralogy, the content of SOC or SOM and soil water. Estimates of these attributes have also been shown to be the most robust. Several other soil attributes, such as $\mathrm{pH}$, nutrients, elements, are often shown to be accurately predicted by some studies, but 
not by others. The explanation for this is the lack of direct relationships between the spectra and soil properties like $\mathrm{pH}, \mathrm{CEC}$, nutrients, etc. We therefore have to assume these parameters are largely predicted through co-variations with water, organics and/or minerals. For example $\mathrm{pH}$ is most probably predicted through co-variations with the buffering capacity of organic matter, clay, and mineralogy, and microbial processes governed by the same soil properties including organic matter quality. These secondary calibrations are less robust. They can be assumed to work best over geographical areas with a homogenous geological and anthropogenic history.

This said, calibrations that perform well for moisture, texture, and organic carbon should not be taken for granted. For clay and organic carbon the relatively large and comparable number of studies indicated that the diversity of the predicted parameter in the individual sample sets explained a great deal of the variability in performance, but far from all. The generalization capacity of diffuse reflectance calibrations is thus an important issue that requires more attention. We suggest that interactions between moisture, mineralogy, and organic matter in spectra need more attention in research in addition to how such interactions influence the prediction capacity of calibrations. To a large extent these three entities absorb, or are influential in coinciding or overlapping bands and their interactions will regulate the trade-off between the generalization capacity and accuracy of prediction models.

Similarly it is important to identify potential mechanisms for predictions through secondary relationships. These are bound to vary with the situation and for some parameters, like plant available $\mathrm{P}$ and total $\mathrm{N}$ there are indications of specific spectral features as well as co-variations behind relationships to the visNIR. Well evaluated sampling and calibration strategies are required for vis-NIR ever to be accepted as a reliable method. Without better knowledge about what is actually measured, progress in this area will be slow.

To reach full potential of vis-NIR spectroscopy field measurements are required. The gains for just replacing standard soil analytical methods in the laboratory is useful but limited, as sampling and sample preparation is a considerable part of the process. Proximal soil sensing by vis-NIR spectroscopy has potential for the measurement of soil attributes. Although there are several environmental and technical issues to consider regarding sample presentation, surface conditions, reproducibility and moisture, there are also several studies that indicate that field sampled spectra are not necessarily worse than laboratory spectra. The denser sampling achieved by proximal sensing might counteract the potentially larger prediction errors. However, for field spectra it appears even more important than for laboratory spectra to be aware of the influences of variations in mineralogy, water, organic matter and, not least, of their interactions. There is lack of published systematic experiments in this area in addition to systematic experiments on the influence and identification of artificial noise in spectra, such as spectrum contamination of plant residues, stones cracks, etc.

Over the last couple of years a few papers have been published that report soil profile measurements with vis-NIR. The development of technology in this area is particularly interesting as there are very few other proximal techniques for three-dimensional soil mapping of specific soil parameters. There are a couple of options for vis-NIR profiling: one is to take a core and measure it ex situ, the other is to drill a hole or use a force probe and make the measurements down the profile in situ. There are advantages for each and some developments in this area are currently occurring.

Regardless if the intention of a calibration is laboratory or field analyses, well thought-out strategies for sampling and calibration are needed. Awareness of the required precision for a specific application has to be put in focus for strategy development. In this review we have not discussed the potential influence of the size of a calibration as few studies consider this. However, there are some recent indications that data mining techniques for calibration might handle the huge variability of soil and the interacting spectral features in the vis-NIR better than linear calibration techniques. 
Finally, soil spectroscopy has been researched for more than 30 years, and the numbers of papers on visNIR in soil science journals has increased exponentially over the last 20 year. Obviously the technique is useful and it can be used to estimate properties such as SOM, mineral composition, clay content and water, and many studies show that we can predict properties such as $\mathrm{pH}$ and nutrients although there are no definitive results. We need to develop theoretical calibrations. To better learn to handle the variability and complexity of soil in soil spectroscopy we need more strategic and collaborative research to gain a better understanding of the physical basis for the reflection of light from soils. We need to also find cleverer uses for the spectra - we know that the spectrum is an integrative property of the soil that tells us about its mineral and organic composition. Therefore spectra could be used directly in soil mapping, for monitoring soil, for making inferences about its quality and function, and making geomorpholocial interpretations of its distribution. In order to do this, we need to be more strategic about what we do. Initiatives such as the development of the Global Soil Spectral Library (Viscarra Rossel, 2009) may provide a way by which to do this. The Global library project aims to develop a global collaborative network for soil spectroscopy to further research and development and encourage its adoption in soil science.

\section{References}

Andrist-Rangel, Y., Simonsson, M., Andersson, S., O“ born, I., and Hillier, S. (2006). Mineralogical budgeting of potassium in soil: A basis for understanding standard measures of reserve potassium. J. Plant Nutr. Soil Sci. 169, 605-615.

Awiti, A. O., Walsh, M. G., Shepherd, K. D., and Kinyamario, J. (2008). Soil condition classification using infrared spectroscopy: A proposition for assessment of soil condition along a tropical forestcropland chronosequence. Geoderma 143, 73-84.

Barnes, R. J., Dhanoa, M. S., and Lister, S. J. (1989). Standard normal variate transformation and detrending of near-infrared diffuse reflectance spectra. Appl. Spectrosc. 43, 772-777.

Barthes, B. G., Brunet, D., Ferrer, H., Chotte, J. L., and Feller, C. (2006). Determination of total carbon and nitrogen content in a range of tropical soils using near infrared spectroscopy: Influence of replication and sample grinding and drying. J. Near Infrared Spectrosc. 14, 341-348.

Baumgardner, M. F., Silva, L. F., Biehl, L. L., and Stoner, E. R. (1985). Reflectance properties of soils. Adv. Agron. 38, 2-44.

Ben-Dor, E., and Banin, A. (1990). Near-infrared reflectance analysis of carbonate concentration in soils. Appl. Spectrosc. 44, 1064-1069.

Ben-Dor, E., and Banin, A. (1994). Visible and near-infrared (0.4-1.1 mum) analysis of arid and semiarid soils. Remote Sens. Environ. 48, 261-274.

Ben-Dor, E., and Banin, A. (1995a). Near-infrared analysis as a rapid method to simultaneously evaluate several soil properties. Soil Sci. Soc. Am. J. 59, 364-372.

Ben-Dor, E., and Banin, A. (1995b). Near infrared analysis (NIRA) as a method to simultaneously evaluate spectral featureless constituents in soils. Soil Sci. 159, 259-270.

Ben-Dor, E., Irons, J. R., and Epema, G. F. (1999). Soil reflectance. In "Remote Sensing for the Earth Sciences: Manual of Remote Sensing”, (A. N. Rencz, Ed.), Vol. 3, pp. 111-188. (3rd edn.). Wiley, New York.

Ben-Dor, E., Heller, D., and Chudnovsky, A. (2008). A novel method of classifying soil profiles in the field using optical means. Soil Sci. Soc. Am. J. 72, 1113-1123.

Bishop, J. L., Pieters, C. M., and Edwards, J. O. (1994). Infrared spectroscopic analyses on the nature of water in montmorillonite. Clays Clay Minerals 42, 702-716. 
Blum, W. E. H. (1993). Soil protection concept of the council of Europe and integrated soil research. In "Integrated Soil and Sediment Research: A Basis for Proper Protection" (H. J. P. Eijsackers and T. Hamers, Eds.), pp. 37-47. Kluwer Academic Publishers, Dordrecht, The Netherlands.

Bogrekci, I., and Lee, W. S. (2005). Spectral soil signatures and sensing phosphorus. Biosyst. Eng. 92, 527-533.

Bokobza, L. (1998). Near infrared spectroscopy. J. Near Infrared Spectrosc. 6, 3-17.

Börjesson, T., Stenberg, B., Lindén, B., and Jonsson, A. (1999). NIR spectroscopy, mineral nitrogen analysis and soil incubations for the prediction of crop uptake of nitrogen during the growing season. Plant Soil 214, 75-83.

Bouma, J. (1997). Soil environmental quality: A European perspective. J. Environ. Qual. 26, 26-31.

Bowers, S. A., and Hanks, R. J. (1965). Reflection of radiant energy from soils. Soil Sci. 100, 130-138.

Bray, J. G. P., Rossel, R. V., and McBratney, A. B. (2009). Diagnostic screening of urban soil contaminants using diffuse reflectance spectroscopy. Aust. J. Soil Res. 47, 433-442.

Bricklemyer, R. S., Miller, P. R., Paustian, K., Keck, T., Nielsen, G. A., and Antle, J. M. (2005). Soil organic carbon variability and sampling optimization in Montana dryland wheat fields. J. Soil Water Conserv. 60, 42-51.

Brown, D. J. (2007). Using a global vis-NIR soil-spectral library for local soil characterization and landscape modeling in a 2nd-order Uganda watershed. Geoderma 140, 444-453.

Brown, D. J., Bricklemyer, R. S., and Miller, P. R. (2005). Validation requirements for diffuse reflectance soil characterization models with a case study of vis-NIR soil C prediction in Montana. Geoderma 129, 251-267.

Brown, D. J., Shepherd, K. D., Walsh, M. G., Mays, M. D., and Reinsch, T. G. (2006). Global soil characterization withVNIRdiffuse reflectance spectroscopy. Geoderma 132, 273-290.

Bullock, P. R., Li, X., and Leonardi, L. (2004). Near-infrared spectroscopy for soil water determination in small soil volumes. Can. J. Soil. Sci. 84, 333-338.

Ce'cillon, L., Cassagne, N., Czarnes, S., Gros, R., and Brun, J. J. (2008). Variable selection in near infrared spectra for the biological characterization of soil and earthworm casts. Soil Biol. Biochem. 40, $1975-1979$.

Chang, C. W., and Laird, D. A. (2002). Near-infrared reflectance spectroscopic analysis of soil C and N. Soil Sci. 167, 110-116.

Chang, C. W., Laird, D. A., Mausbach, M. J., and Hurburgh, C. R. (2001). Near-infrared reflectance spectroscopy-principal components regression analyses of soil properties. Soil Sci. Soc. Am. J. 65, 480490.

Chang, G. W., Laird, D. A., and Hurburgh, G. R. (2005). Influence of soil moisture on near-infrared reflectance spectroscopic measurement of soil properties. Soil Sci. 170, 244-255.

Chodak, M., Ludwig, B., Partap, K., Beese, F., and Khanna, P. (2002). Use of near infrared spectroscopy to determine biological and chemical characteristics of organic layers under spruce and beech stands. J. Plant Nutr. Soil Sci. 165, 27-33.

Chodak, M., Niklinska, M., and Beese, F. (2007). Near-infrared spectroscopy for analysis of chemical and microbiological properties of forest soil organic horizons in a heavymetal-polluted area. Biol. Fertil. Soils 44, 171-180. 
Christy, C. D. (2008). Real-time measurement of soil attributes using on-the-go near infrared reflectance spectroscopy. Comput. Electron. Agric. 61, 10-19.

Clark, R. N. (1999). Spectroscopy of rocks and minerals and principles of spectroscopy. In "Remote Sensing for the Earth Sciences"' (A. N. Rencz, Ed.), pp. 3-58. John Wiley \& Sons, Chichester, UK.

Clark, R. N., King, T. V. V., Klejwa, M., Swayze, G. A., and Vergo, N. (1990). High spectral resolution reflectance spectroscopy of minerals. J. Geophys. Res. 95, 12653-12680.

Couteaux, M.-M., Berg, B., and Rovira, P. (2003). Near infrared reflectance spectroscopy for determination of organic matter fractions including microbial biomass in coniferous forest soils. Soil Biol. Biochem. 35, 1587-1600.

Dahm, D. J., and Dahm, K. D. (2007). Interpreting Diffuse Reflectance and Transmittance - A Theoretical Introduction to Absorption Spectroscopy of Scattering Materials NIR Publications, Chichester, UK.

Dalal, R. C., and Henry, R. J. (1986). Simultaneous determination of moisture, organic carbon, and total nitrogen by near infrared reflectance spectrophotometry. Soil Sci. Soc. Am. J. 50, 120-123.

Daniel, K. W., Tripathi, N. K., and Honda, K. (2003). Artificial neural network analysis of laboratory and in situ spectra for the estimation of macronutrients in soils of Lop Buri (Thailand). Aust. J. Soil Res. 41, $47-59$.

Dematte, J. A. M., Campos, R. C., Alves, M. C., Fiorio, P. R., and Nanni, M. R. (2004). Visible-NIR reflectance: A new approach on soil evaluation. Geoderma 121, 95-112.

Dunn, B., Beecher, G., Batten, G., and Blakeny, A. (2000). Estimating the uptake of nitrogen by rice crops using near infrared reflectance analysis of soil. In "Near Infrared Spectroscopy: Proceedings of the 9th International Conference', (A. M. C. Davies and R. Giangiacomo, Eds.), pp. 565-568. NIR Publications, Chichester, UK/Verona, Italy.

Dunn, B. W., Beecher, H. G., Batten, G. D., and Ciavarella, S. (2002). The potential of near-infrared reflectance spectroscopy for soil analysis - A case study from the Riverine Plain of south- eastern Australia. Aust. J. Exp. Agric. 42, 607-614.

Ehsani, M. R., Upadhyaya, S. K., Slaughter, D., Shafii, S., and Pelletier, M. (1999). A NIR technique for rapid determination of soil mineral nitrogen. Precision Agric. 1, 217-234.

Everitt, B. S. (2002). The Cambridge Dictionary of Statistics 2nd edn. Cambridge University Press, Cambridge, UK.

Farmer, V. C., (Ed.) (1974). The Infra-Red Spectra of Minerals, pp. 1-539. Mineralogical Society, London.

Fidencio, P. H., Poppi, R. J., and de Andrade, J. C. (2002). Determination of organic matter in soils using radial basis function networks and near infrared spectroscopy. Anal. Chim. Acta 453, 125-134.

Fox, R. H., Shenk, J. S., Piekielek, W. P., Westerhaus, M. O., Toth, J. D., and Macneal, K. E. (1993). Comparison of near-infrared spectroscopy and other soil nitrogen availability quick tests for corn. Agron. J. 85, 1049-1053.

Fystro, G. (2002). The prediction of $\mathrm{C}$ and $\mathrm{N}$ content and their potential mineralisation in heterogeneous soil samples using Vis-NIR spectroscopy and comparative methods. Plant Soil 246, 139-149.

Geladi, P., Macdougall, D., and Martens, H. (1985). Linearization and scatter-correction for near-infrared reflectance spectra of meat. Appl. Spectrosc. 39, 491-500.

Goddu, R. F., and Delker, D. A. (1960). Spectra-structure correlations for the near-infrared region. Anal. Chem. 32, 140-141. 
Groenigen, J. W., Mutters, C. S., Horwath, W. R., and Kessel, C. (2003). NIR and DRIFT-MIR spectrometry of soils for predicting soil and crop parameters in a flooded field. Plant Soil 250, 155-165.

Harris, R. F., Karlen, D. L., and Mulla, D. J. (1996). A conceptual framework for assessment and management of soil quality and health. In "Methods for Assesssing Soil Quality" (A. J. Jones and J. W. Doran, Eds.), Vol. 49, pp. 61-82. SSSA, Madison, WI Special Publication.

Henderson, T. L., Baumgardner, M. F., Franzmeier, D. P., Stott, D. E., and Coster, D. C. (1992). High dimensional reflectance analysis of soil organic-matter. Soil Sci. Soc. Am. J. 56, 865-872.

Hillel, D., and Hillel, D. (1998). Environmental Soil Physics Academic Press Ltd, London.

Hummel, J. W., Sudduth, K. A., and Hollinger, S. E. (2001). Soil moisture and organic matter prediction of surface and subsurface soils using an NIR soil sensor. Comput. Electron. Agric. 32, 149-165.

Hunt, G. R. (1977). Spectral signatures of particulate minerals in visible and near-infrared. Trans. Am. Geophys. Union 58, 553.

Hunt, G. R., and Salisbury, J. W. (1970). Visible and near-infrared spectra of minerals and rocks. I. Silicate minerals. Mod. Geol. 1, 283-300.

Islam, K., Singh, B., and McBratney, A. (2003). Simultaneous estimation of several soil properties by ultra-violet, visible, and near-infrared reflectance spectroscopy. Aust. J. Soil Res. 41, 1101-1114.

Islam, K., McBratney, A., and Singh, B. (2005). Rapid estimation of soil variability from the convex hull biplot area of topsoil ultra-violet, visible and near-infrared diffuse reflectance spectra. Geoderma 128, 249-257.

Jarvis, N. J. (2007). A review of non-equilibrium water flow and solute transport in soil macropores: Principles, controlling factors and consequences for water quality. Eur. J. Soil Sci. 58, 523-546.

Jenny, H. (1980). The Soil Resource Springer, Berlin German Federal Republic.

Kang, S. H., and Xing, B. S. (2005). Phenanthrene sorption to sequentially extracted soil humic acids and humins. Environ. Sci. Technol. 39, 134-140.

Karlen, D. L., Mausbach, M. J., Doran, J. W., Cline, R. G., Harris, R. F., and Schuman, G. E. (1997). Soil quality: A concept, definition, and Framework for Evaluation. Soil Sci. Soc. Am. J. 61, 4-10.

Kemper, T., and Sommer, S. (2002). Estimate of heavy metal contamination in soils after a mining accident using reflectance spectroscopy. Environ. Sci. Technol. 36, 2742-2747.

Kooistra, L., Wehrens, R., Leuven, R. S. E. W., and Buydens, L. M. C. (2001). Possibilities of visiblenear-infrared spectroscopy for the assessment of soil contamination in river floodplains. Anal. Chim. Acta $446,97-105$.

Krischenko, V. P., Samokhvalov, S. G., Fomina, L. G., and Novikova, G. A. (1992). Use of infrared spectroscopy for the determination of some properties of soil. In "Making Light Work: Advances in near Infrared Spectroscopy”'(I. Murray and L. A. Cowe, Eds.), pp. 239-249 (Aberdeen, Scotland).

Krishnan, P., Alexander, D. J., Butler, B., and Hummel, J. W. (1980). Reflectance technique for predicting soil organic matter. Soil Sci. Soc. Am. J. 44, 1282-1285.

Kusumo, B. H., Hedley, M. J., Tuohy, M. P., Hedley, C. P., and Arnold, G. C. (2010). Prediction of soil carbon and nitrogen concentrations and pasture root densities from proximally sensed soil spectral reflectance. In "Proximal Soil Sensing”' (R. A. Viscarra Rosse, A. B. McBRatney, and B. Minasny, Eds.), pp. 177-190. Springer.

Liu, W. D., Baret, F., Gu, X. F., Tong, Q. X., Zheng, L. F., and Zhang, B. (2002). Relating soil surface moisture to reflectance. Remote Sens. Environ. 81, 238-246. 
Lobell, D. B., and Asner, G. P. (2002). Moisture effects on soil reflectance. Soil Sci. Soc. Am. J. 66, 722727.

Ludwig, B., Khanna, P. K., Bauhus, J., and Hopmans, P. (2002). Near infrared spectroscopy of forest soils to determine chemical and biological properties related to soil sustainability. For. Ecol. Manag. 171, 121132.

Madejova, J., and Komadel, P. (2001). Baseline studies of the clay minerals society source clays: infrared methods. Clays Clay Minerals 49, 410-432.

Maleki, M. R., van Holm, L., Ramon, H., Merckx, R., De Baerdemaeker, J., and Mouazen, A. M. (2006). Phosphorus sensing for fresh soils using visible and near infrared spectroscopy. Biosyst. Eng. 95, 425436.

Maleki, M. R., Mouazen, A. M., De Keterlaere, B., Ramon, H., and De Baerdemaeker, J. (2008). On-thego variable-rate phosphorus fertilisation based on a visible and near infrared soil sensor. Biosyst. Eng. 99, $35-46$.

Malley, D. F., and Williams, P. C. (1997). Use of near-infrared reflectance spectroscopy in prediction of heavy metals in freshwater sediment by their association with organic matter. Environ. Sci. Technol. 31, 3461-3467.

Malley, D. F., Martin, P. D., McClintock, L. M., Yesmin, L., Eilers, R. G., and Haluschak, P. (2000). Feasibility of analysing archived Canadian prairie agricultural soils by near infrared reflectance spectroscopy. In "Near Infrared Spectroscopy: Proceedings of the 9th International Conference" (A. M. C. Davies and R. Giangiacomo, Eds.), pp. 579-585. NIR Publications, Chichester, UK.

Mamo, T., Richter, C., and Heiligtag, B. (1996). Comparison of extractants for the determination of available phosphorus, potassium, calcium, magnesium and sodium in some Ethiopian and German soils. Commun. Soil Sci. Plant Anal. 27, 2197-2212.

Martens, H., and Naes, T. (1989). Multivariate Calibration John Wiley \& Sons, Chichester, UK. 419 pp.

Martin, P. D., Malley, D. F., Manning, G., and Fuller, L. (2002). Determination of soil organic carbon and nitrogen at the field level using near-infrared spectroscopy. Can. J. Soil. Sci. 82, 413-422.

McCarty, G. W., and Reeves, J. B. III (2006). Comparison of near infrared and mid infrared diffuse reflectance spectroscopy for field-scale measurement of soil fertility parameters. Soil Sci. 171, 94-102.

Meder, R., Beets, P. N., and Oliver, G. R. (2007). Multivariate analysis of IR, NIR, and NMR spectra of soil samples from different land use conversions: Native forest, pasture, and plantation forest. N. Z. J. For. Sci. 37, 289-305.

Mehlich, A. (1984). Mehlich-3 soil test extractant-A modification of mehlich-2 extractant. Commun. Soil Sci. Plant Anal. 15, 1409-1416.

Miller, C. E. (2001). Chemical principles of near-infrared technology. In "Near-Infrared Technology in the Agricultural and Food Industries" (P. Williams and K. Norris, Eds.), pp. 19-37. The American Association of Cereal Chemists Inc., St. Paul, MN.

Mooney, S., Antle, J., Capalbo, S., and Paustian, K. (2004). Influence of project scale and carbon variability on the costs of measuring soil carbon credits. Environ. Manage. 33, S252-S263.

Moron, A., and Cozzolino, D. (2002). Application of near infrared reflectance spectroscopy for the analysis of organic $\mathrm{C}$, total $\mathrm{N}$ and $\mathrm{pH}$ in soils of Uruguay. J. Near Infrared Spectrosc. 10, 215-221.

Moron, A., and Cozzolino, D. (2003). Exploring the use of near infrared reflectance spectroscopy to study physical properties and microelements in soils. J. Near Infrared Spectrosc. 11, 145-154. 
Morra, M. J., Hall, M. H., and Freeborn, L. L. (1991). Carbon and nitrogen analysis of soil fractions using near-infrared reflectance spectroscopy. Soil Sci. Soc. Am. J. 55, 288-291.

Morris, R. V., Lauer, H. V., Lawson, C. A., Gibson, E. K., Nace, G. A., and Stewart, C. (1985). Spectral and other physicochemical properties of submicron powders of hematite (Alpha-Fe2o3), maghemite (Gamma-Fe2o3), magnetite (Fe3o4), goethite (Alpha-Feooh), and lepidocrocite (Gamma-Feooh). J. Geophys. Res. 90, 3126-3144.

Mortimore, J. L., Marshall, L. J. R., Almond, M. J., Hollins, P., and Matthews, W. (2004). Analysis of red and yellow ochre samples from Clearwell Caves and Catalhoyuk by vibrational spectroscopy and other techniques. Spectrochim. Acta A Mol. Biomol. Spectrosc. 60, 1179-1188.

Mouazen, A. M., De Baerdemaeker, J., and Ramon, H. (2005a). Towards development of on-line soil moisture content sensor using a fibre-type NIR spectrophotometer. Soil Tillage Res. 80, 171-183.

Mouazen, A. M., Karoui, R., De Baerdemaeker, J., and Ramon, H. (2005b). Classification of soil texture classes by using soil visual near infrared spectroscopy and factorial discriminant analysis techniques. J. Near Infrared Spectrosc. 13, 231-240.

Mouazen, A. M., De Baerdemaeker, J., and Ramon, H. (2006a). Effect of wavelength range on the measurement accuracy of some selected soil constituents using visual-near infrared spectroscopy. J. Near Infrared Spectrosc. 14, 189-199.

Mouazen, A. M., Karoui, R., De Baerdemaeker, J., and Ramon, H. (2006b). Characterization of soil water content using measured visible and near infrared spectra. Soil Sci. Soc. Am. J. 70, 1295-1302.

Mouazen, A. M., Maleki, M. R., De Baerdemaeker, J., and Ramon, H. (2007). On-line measurement of some selected soil properties using a VIS-NIR sensor. Soil Tillage Res. 93, 13-27.

Mouazen, A. M., Maleki, M. R., Cockx, L., Van Meirvenne, M., Van Holm, L. H. J., Merckx, R., de Baerdemaeker, J., and Ramon, H. (2009). Optimum three-point linkage set up for improving the quality of soil spectra and the accuracy of soil phosphorus measured using an on-line visible and near infrared sensor. Soil Tillage Res. 103, 144-152.

Mouazen, A. M., Kuang, B., De Baerdemaeker, J., and Ramon, H. (2010). Comparison between principal component, partial least squares and artificial neural network analyses for accuracy of measurement of selected soil properties with visible and near infrared spectroscopy. Geoderma 158, 23-31.

Odlare, M., Svensson, K., and Pell, M. (2005). Near infrared reflectance spectroscopy for assessment of spatial soil variation in an agricultural field. Geoderma 126, 193-202.

Palmborg, C., and Nordgren, A. (1993). Modelling microbial activity and biomass in forest soil with substrate quality measured using near infrared reflectance spectroscopy. Soil Biol. Biochem. 25, 17131718 .

Pereira, A. G., Go'mez, A. H., and He, Y. (2004). Near-infrared spectroscopy potential to predict N, P, K and $\mathrm{OM}$ content in a loamy mixed soil and its combination with precision farming. In "CIGR International Conference Beijing,'” Beijing, China.

Pietkäinen, J., and Fritze, H. (1995). Clear-cutting and prescribed burning in coniferous forest: Comparision of effects on soil fungal and total microbial biomass, respiration activity and nitrification. Soil Biol. Biochem. 27, 101-109.

Pirie, A., Singh, B., and Islam, K. (2005). Ultra-violet, visible, near-infrared, and mid-infrared diffuse reflectance spectroscopic techniques to predict several soil properties. Aust. J. Soil Res. 43, 713-721.

Post, J. L., and Noble, P. N. (1993). The near-infrared combination band frequencies of dioctahedral smectites, micas, and illites. Clays Clay Minerals 41, 639-644. 
Reeves, J. B. III, McCarty, G. W., and Meisinger, J. J. (1999). Near infrared reflectance spectroscopy for the analysis of agricultural soils. J. Near Infrared Spectrosc. 7, 179-193.

Reeves, J. B. III, Follett, R. F., McCarty, G. W., and Kimble, J. M. (2006). Can near or mid-infrared diffuse reflectance spectroscopy be used to determine soil carbon pools? Commun. Soil Sci. Plant Anal. $37,2307-2325$.

Rinnan, R., and Rinnan, A. (2007). Application of near infrared reflectance (NIR) and fluorescence spectroscopy to analysis of microbiological and chemical properties of arctic soil. Soil Biol. Biochem. 39, 1664-1673.

Robert, P. C., Thompson, W. H., and Fairshild, D. (1991). Soil specific anhydrous ammonia management system. "Symposium on Automated Agriculture for the $21^{\text {st }}$ century", pp. 418-426. ASAE, St Joseph, MI.

Russell, C. A. (2003). Sample preparation and prediction of soil organic matter properties by near infrared reflectance spectroscopy. Commun. Soil Sci. Plant Anal. 34, 1557-1572.

Russell, C. A., Angus, J. F., Batten, G. D., Dunn, B. W., and Williams, R. L. (2002). The potential of NIR spectroscopy to predict mineralization in rice soils. Plant Soil 247, 243-252.

Sankey, J. B., Brown, D. J., Bernard, M. L., and Lawrence, R. L. (2008). Comparing local vs global visible and near-infrared (VisNIR) diffuse reflectance spectroscopy (DRS) calibrations for the prediction of soil clay, organic C and inorganic C. Geoderma 148, 149-158.

Savitzky, A., and Golay, M. (1964). Smoothing and differentiation of data by simplified least squares procedures. Anal. Chem. 36, 1627-1639.

Schuller, H. (1969). Die CAL-Methode, eine neue Methode zur Bestimmung des Pflanzenverfugbaren Phosphates in Böden. Z Pflanzenkr Bodenkunde 123, 48-63.

Schulze, D. G. (2002). An introduction to soil mineralogy. In "Soil Mineralogy with Environmental Applications" (J. B. Dixon and D. G. Schulze, Eds.), pp. 1-35. Soil Science Society of America Inc., Madison, WI.

Shepherd, K. D., and Walsh, M. G. (2002). Development of reflectance spectral libraries for characterization of soil properties. Soil Sci. Soc. Am. J. 66, 988-998.

Shepherd, K. D., and Walsh, M. G. (2007). Infrared spectroscopy-Enabling an evidencebased diagnostic surveillance approach to agricultural and environmental management in developing countries. J. Near Infrared Spectrosc. 15, 1-20.

Sherman, D. M., and Waite, T. D. (1985). Electronic spectra of Fe3p oxides and oxyhydroxides in the near infrared to ultraviolet. Am. Mineral. 70, 1262-1269.

Shibusawa, S., Sato, H. P., Hirako, S., Otomo, A., and Sasao, A. (2000). A revised soil spectrophotometer. "IFAC Bio-Robotics, Information Technology and Inteligent Control for Bio Production Systems", pp. 231-236. Sakai, Osaka, Japan.

Shibusawa, S., Made Anom, S. W., Sato, H. P., and Sasao, A. (2001). Soil mapping using the real-time soil spectrometer. In "ECPA 2001" (G. Gerenier and S. Blackmore, Eds.), Vol. 2, pp. 485-490. agro Montpellier, Montpellier, France. Shonk, J. L., Gaultney, L. D., Schulze, D. G., and Scoyoc, G. E. V. (1991). Spectroscopic sensing of soil organic matter content. Trans. ASAE 34, 1978-1984.

Siebielec, G., McCarty, G. W., Stuczynski, T. I., and Reeves, J. B. III (2004). Near- and mid-infrared diffuse reflectance spectroscopy for measuring soil metal content. J. Environ. Qual. 33, 2056-2069. 
Skjemstad, J. O., Clarke, P., Golchin, A., and Oades, J. M. (1997). Characterization of soil organic matter by solid-state 13C NMR spectroscopy. In "Driven by nature: Plant litter quality and decomposition" (G. Gadish and K. E. Giller, Eds.), pp. 253-271. CAB International, Wellington, UK.

Slaughter, D. C., Pelletier, M. G., and Upadhyaya, S. K. (2001). Sensing soil moisture using NIR spectroscopy. Appl. Eng. Agric. 17, 241-247.

Sörensen, L. K., and Dalsgaard, S. (2005). Determination of clay and other soil properties by near infrared spectroscopy. Soil Sci. Soc. Am. J. 69, 159-167.

Stenberg, B. (2010). Effects of soil sample pretreatments and standardised rewetting as interacted with sand classes on Vis-NIR predictions of clay and soil organic carbon. Geoderma. 158, 15-22.

Stenberg, B. (1999). Monitoring soil quality of arable land: Microbiological indicators. Acta Agric. Scand., Sect. B, Soil and Plant Sci. 49, 1-24.

Stenberg, B., and Nordkvist, E. (1996). Near infrared reflectance measurements to assess the chemical and physical variations in arable soils. In "Near Infrared Spectroscopy: The Future Waves" (A. M. C. Davies and P. Williams, Eds.), pp. 498-504. NIR Publications, Chichester, UK/Montreal, Canada.

Stenberg, B., Nordkvist, E., and Salomonsson, L. (1995). Use of near infrared reflectance spectra of soils for objective selection of samples. Soil Sci. 159, 109-114.

Stenberg, B., Pell, M., and Torstensson, L. (1998). Integrated evaluation of variation in biological, chemical and physical soil properties. Ambio 27, 9-15.

Stenberg, M., Aronsson, H., Linden, B., Rydberg, T., and Gustafson, A. (1999). Soil mineral nitrogen and nitrate leaching losses in soil tillage systems combined with a catch crop. Soil Tillage Res. 50, 115-125.

Stenberg, B., Jonsson, A., and Bo“ rjesson, T. (2000). Snabbmetoder för bestämning av lerhalt och kalkbehov med hjälp av NIR-analys. (Rep. No. 2000-2. ODAL FoU, Lidköping).

Stenberg, B., Jonsson, A., and Börjesson, T. (2002). Near infrared technology for soil analysis with implications for precision agriculture. In "Near Infrared Spectroscopy: Proceedings of the 10th International Conference', (A. Davies and R. Cho, Eds.), pp. 279-284. NIR Publications, Chichester, UK.

Stenberg, B., Jonsson, A., and Boörjesson, T. (2005). Use of near infrared reflectance spectroscopy to predict nitrogen uptake by winter wheat within fields with high variability in organic matter. Plant Soil 269, 251-258.

Stenberg, B., Rogstrand, G., Bolenius, E., and Arvidsson, J. (2007). On-line soil NIR spectroscopy: Identification and treatment of spectra influenced by variable probe distance and residue contamination. In "Precision agriculture '07. Papers presented at the 6th European Conference on Precision Agriculture, Skiathos, Greece, 3-6 June, 2007' ( J. V. Stafford, Ed.), pp. 125-131. Wageningen Academic Publishers, Wageningen, The Netherlands.

Sudduth, K. A., and Hummel, J. W. (1993a). Portable, near-infrared spectrophotometer for rapid soil analysis. Trans. ASAE 36, 185-193.

Sudduth, K. A., and Hummel, J. W. (1993b). Soil organic matter, CEC, and moisture sensing with a portable NIR spectrophotometer. Trans. ASAE 36, 1571-1582.

Sudduth, K. A., and Hummel, J. W. (1996). Geographic operating range evaluation of a NIR soil sensor. Trans. ASAE 39, 1599-1604.

Sudduth, K. A., Hummel, J. W., and Funk, R. C. (1989). NIR soil organic matter sensor. Paper - can Society of Agricultural Engineers, 23 pp. 
Terhoeven-Urselmans, T., Michel, K., Helfrich, M., Flessa, H., and Ludwig, B. (2006). Near-infrared spectroscopy can predict the composition of organic matter in soil and litter. J. Plant Nutr. Soil Sci. 169, $168-174$.

Twomey, S. A., Bohren, C. F., and Mergenthaler, J. L. (1986). Reflectance and albedo differences between wet and dry surfaces. Appl. Optics 25, 431-437.

Udelhoven, T., Emmerling, C., and Jarmer, T. (2003). Quantitative analysis of soil chemical properties with diffuse reflectance spectrometry and partial least-square regression: A feasibility study. Plant Soil 251, 319-329.

Upadhyaya, S. K., Shafii, S., and Slaughter, D. (1994). Sensing soil nitrogen for specific crop management (SSCM).(Paper - an Society of Agricultural Engineers, 29 pp.).

Vågen, T. G., Shepherd, K. D., and Walsh, M. G. (2006). Sensing landscape level change in soil fertility following deforestation and conversion in the highlands of Madagascar using Vis-NIR spectroscopy. Geoderma 133, 281-294.

van Groenigen, J. W., Mutters, C. S., Horwath, W. R., and van Kessel, C. (2003). NIR and DRIFT-MIR spectrometry of soils for predicting soil and crop parameters in a flooded field. Plant Soil 250, 155-165.

Viscarra Rossel, R. A. (2007). Robust modelling of soil diffuse reflectance spectra by "bagging-partial least squares regression'. J. Near Infrared Spectrosc. 15, 39-47.

Viscarra Rossel, R. A. (2008). ParLeS: Software for chemometric analysis of spectroscopic data. Chemom. Intell. Lab. Syst. 90, 72-83.

Viscarra Rossel, R. A. (2009). The Soil Spectroscopy Group and the development of a global soil spectral library. NIR News 20, 17-18.

Viscarra Rossel, R. A., and Behrens, T. (2010). Using data mining to model and interpret soil diffuse reflectance spectra. Geoderma 158, 46-54.

Viscarra Rossel, R. A., and Lark, R. M. (2009). Improved analysis and modelling of soil diffuse reflectance spectra using wavelets. Eur. J. Soil Sci. 60, 453-464.

Viscarra Rossel, R. A., and McBratney, A. B. (1998). Laboratory evaluation of a proximal sensing technique for simultaneous measurement of soil clay and water content. Geoderma 85, 19-39.

Viscarra Rossel, R. A., and McBratney, A. B. (2008). Diffuse reflectance spectroscopy as a tool for digital soil mapping. In "Digital Soil Mapping with Limited Data" (Mc Bratney A. B. Hartemink AE and L. Mendonc,a-Santos, Eds.), Developments in Soil Science Series, Elsevier Science, Amsterdam.

Viscarra Rossel, R. A., McGlynn, R. N., and McBratney, A. B. (2006a). Determing the composition of mineral-organic mixes using UV-vis-NIR diffuse reflectance spectroscopy. Geoderma 137, 70-82.

Viscarra Rossel, R. A., Minasny, B., Roudier, P., and McBratney, A. B. (2006b). Colour space models for soil science. Geoderma 133, 320-337.

Viscarra Rossel, R. A., Walvoort, D. J. J., McBratney, A. B., Janik, L. J., and Skjemstad, J. O. (2006c). Visible, near infrared, mid infrared or combined diffuse reflectance spectroscopy for simultaneous assessment of various soil properties. Geoderma 131, 59-75.

Viscarra Rossel, R. A., Jeon, Y. S., Odeh, I. O. A., and McBratney, A. B. (2008a). Using a legacy soil sample to develop a mid-IR spectral library. Aust. J. Soil Res. 46, 1-16.

Viscarra Rossel, R. A., Fouad, Y., and Walter, C. (2008b). Using a digital camera to measure soil organic carbon and iron contents. Biosyst. Eng. 100, 149-159. 
Viscarra Rossel, R. A., Cattle, S. R., Ortega, A., and Fouad, Y. (2009). In situ measurements of soil colour, mineral composition and clay content by vis-NIR spectroscopy. Geoderma 150, 253-266.

Viscarra Rossel, R. A., Rizzo, R., Demattê, J. A. M., and Behrens, T. (2010). Spatial modelling of a soil fertility index using vis-NIR spectra and terrain attributes. Soil Sci. Soc. Am. J. 74, 1293-1300.

Wagner, B., Gutser, R., and Schmidhalter, U. (2001). NIR-spectroscopy to estimate soil nitrogen supply. In "Plant Nutrition-Food Security and Sustainability of Agro-Ecosystems" (W. J. Horst, Ed.), pp. 752753. Kluwer Academic Publishers, Dordrecht, The Netherlands.

Waiser, T. H., Morgan, C. L. S., Brown, D. J., and Hallmark, C. T. (2007). In situ characterization of soil clay content with visible near-infrared diffuse reflectance spectroscopy. Soil Sci. Soc. Am. J. 71, 389-396.

Wetterlind, J., Stenberg, B., and Jonsson, A. (2008a). Near infrared reflectance spectroscopy compared with soil clay and organic matter content for estimating within-field variation in $\mathrm{N}$ uptake in cereals. Plant Soil 302, 317-327.

Wetterlind, J., Stenberg, B., and Söderström, M. (2008b). The use of near infrared (NIR) spectroscopy to improve soil mapping at the farm scale. Precision Agric. 9, 57-69.

Wetterlind, J., Stenberg, B., and Söderström, M. (2010). Increased sample point density in farm soil mapping by local calibration of visible and near infrared prediction models. Geoderma 156, 152-160.

Whalley, W. R., Leedsharrison, P. B., and Bowman, G. E. (1991). Estimation of soil-moisture status using near-infrared reflectance. Hydrol. Process. 5, 321-327.

Wold, S., Antti, H., Lindgren, F., and O“ hman, J. (1998). Orthogonal signal correction of near-infrared spectra. Chemom. Intell. Lab. Syst. 44, 175-785.

Wu, Y., Chen, J., Ji, J., Tian, Q., Qin, Z., and Wu, X. (2005a). Possibilities of reflectance spectroscopy for the assessment of contaminant elements in suburban soils. Appl. Geochem. 20, 1051-1059.

Wu, Y., Chen, J., Ji, J., Tian, Q., and Wu, X. (2005b). Feasibility of reflectance spectroscopy for the assessment of soil mercury contamination. Environ. Sci. Technol. 39, 873-878.

Wu, Y., Chen, J., Ji, J., Gong, P., Liao, Q., Tian, Q., and Ma, H. (2007). A mechanism study of reflectance spectroscopy for investigating heavy metals in soils. Soil Sci. Soc. Am. J. 71, 918-926.

Xing, B. S., Liu, J. D., Liu, X. B., and Han, X. Z. (2005). Extraction and characterization of humic acids and humin fractions from a black soil of China. Pedosphere 14, 1-8.

Zbiral, J., and Nemec, P. (2002). Comparison of Mehlich 2, Mehlich 3, CAL, Egner, Olsen, and $0.01 \mathrm{MCaCl} 2$ extractants for determination of phosphorus in soils. Commun. Soil Sci. Plant Anal. 33, $3405-3417$. 
